\title{
Molecular Phylogenetics of the Ronnbergia Alliance (Bromeliaceae, Bromelioideae) and insights into their morphological evolution
}

Julián Aguirre-Santoro ${ }^{\mathrm{a}, \mathrm{b}, \mathrm{c}, *}$, Fabián A. Michelangeli ${ }^{\mathrm{a}}$, Dennis W. Stevenson ${ }^{\mathrm{a}}$

aThe New York Botanical Garden, 2900 Southern Boulevard, Bronx, New York 10458, U.S.A.E-mail addresses: jaaguirresa@gmail.com, fabian@nybg.org,dws@nybg.org

${ }^{\mathrm{b}}$ The Graduate Center, City University of New York, $3655^{\text {th }}$ Ave, New York, New York 10016, U.S.A.

${ }^{c}$ Permanent address: Cra. 4 \# 54-59. Apt. 706. Bogotá, Colombia

* Corresponding author. Tel: +57 322-365-7030

E-mail address: jaaguirresa@gmail.com

\begin{abstract}
.
The tank-epiphytic clade of berry-fruited bromeliads, also known as the Core Bromelioideae, represents a remarkable event of adaptive radiation within the Bromeliaceae; however, the details of this radiation have been difficult to study because this lineage is plagued with generic delimitation problems. In this study, we used a phylogenetic approach to investigate a well supported, albeit poorly understood, lineage nested within the Core Bromelioideae, here called the "Ronnbergia Alliance." In order to
\end{abstract}


assess the monophyly and phylogenetic relationships of this group, we used three plastid and three nuclear DNA sequence markers combined with a broad sampling across three taxonomic groups and allied species of Aechmea expected to comprise the Ronnbergia Alliance. We combined the datasets to produce a well-supported and resolved phylogenetic hypothesis. Our main results indicated that the Ronnbergia Alliance was a well-supported monophyletic group, sister to the remaining Core Bromelioideae, and it was composed by species of the polyphyletic genera Aechmea, Hohenbergia and Ronnbergia. We identified two major internal lineages with high geographic structure within the Ronnbergia Alliance. The first of these lineages, called the Pacific Clade, contained species of Aechmea and Ronnbergia that occur exclusively from southern Central America to northwestern South America. The second clade, called the Atlantic Clade, contained species of Aechmea, Hohenbergia and Ronnbergia mostly limited to the Atlantic Forest and the Caribbean. We also explored the diagnostic and evolutionary importance of 13 selected characters using ancestral character reconstructions on the phylogenetic hypothesis. We found that the combination of tubular corollas apically spreading and unappendaged ovules had diagnostic value for the Ronnbergia Alliance, whereas flower size, length of the corolla tube, and petal pigmentation and apex were important characters to differentiate the Pacific and Atlantic clades. This study opens new perspectives for future taxonomic reorganizations and provides a framework for evolutionary and biogeographic studies.

\section{Keywords}

Atlantic Forest, Bromeliaceae, Bromelioideae, Caribbean, Chocó-Tumbes-Magdalena region, Ronnbergia Alliance 


\section{Introduction}

Recent developments in the fields of phylogenetics, biogeography, and comparative biology have allowed the exploration of exciting evolutionary questions across many taxonomic groups. The Bromeliaceae have received special attention because of their clear shifts in adaptive regimes across lineages, high species diversity (ca. 3352 species), and almost exclusively Neotropical geographical distribution (Benzing, 2000; Bouchenak-Khelladi et al., 2015; Givnish et al., 2014). Consequently, recent studies have provided significant advances on the understanding of the phylogenetic relationships and major evolutionary events across the main lineages in the family (Crayn, 2004; Givnish et al., 2014, 2011, 2007, 2004; Givnish and Sytsma, 2000; Quezada and Gianoli, 2011; Silvestro et al., 2014). However, at the generic level and below, the taxonomy and phylogenetic relationships of the Bromeliaceae are still poorly understood (Barfuss et al., 2005; Faria et al., 2004; Sass and Specht, 2010; Schulte et al., 2009). Different studies have approached this problem by focusing on the subfamily Bromelioideae, a monophyletic lineage plagued with generic delimitation problems, but at the same time highly attractive for evolutionary studies because of its high species diversity (ca. 936 species), large mosaic of phenotypic and adaptive variation, and high levels of narrow endemism across the Neotropics (Almeida et al., 2009; Evans et al., 2015; Faria et al., 2004; Heller et al., 2015; Horres et al., 2007; Sass and Specht, 2010; Schulte et al., 2009, 2005; Schulte and Zizka, 2008; Silvestro et al., 2014; Smith and Downs, 1979; Sousa et al., 2007). 
The problems of generic delimitation within Bromelioideae have been discussed since the early taxonomic treatments of Bromeliaceae. For instance, in the latest comprehensive revision of the family, Smith \& Downs (1979) recognized that although characters such as inflorescence ramification, flower pedicels, and petal appendages are important to diagnose genera within Bromelioideae, they could occasionally occur in isolated species placed within the most artificial genera of the subfamily, such as Aechmea. Morphological studies later provided further evidence by showing that these "diagnostic" characters are prone to evolve rapidly and are only of limited taxonomic use (Brown and Terry, 1992; Faria et al., 2004; Schulte and Zizka, 2008). The limitations posed by the lack of unequivocal diagnostic characters have been progressively resolved with the advent of molecular phylogenetics. Recent studies, for example, have shown that the early-diverging lineages of Bromelioideae are generally tankless, terrestrial or lithophytic species, whereas the most recent and diverse lineage encompasses mostly tank-forming, epiphytic species (Evans et al., 2015; Givnish et al., 2011; Sass and Specht, 2010; Schulte et al., 2009; Silvestro et al., 2014). While in the past there have been only few changes in generic concepts for early-diverging Bromelioideae, generic delimitation in the tank-epiphytic clade, also known as the "Core Bromelioideae" (sensu Sass and Specht, 2010), has proven highly problematic and resulted in frequent taxonomic changes over the past decades (e.g. Brown and Leme, 2005; Leme and Kollmann, 2011; Smith and Kress, 1989; Smith and Spencer, 1992).

Phylogenetic resolution within the Core Bromelioideae is still insufficient to propose a thoroughly revised taxonomic classification; however, independent phylogenetic studies have revealed common patterns that can serve as a starting point for 
further investigation. While many genera of the Core Bromeliodeae have been shown to be non-monophyletic, a common pattern is that the several lineages within the Core Bromelioideae that have been identified by molecular phylogenetic studies, are often composed by species that share a similar and narrow geographical distribution (Faria et al., 2004; Sass and Specht, 2010; Schulte et al., 2009; Silvestro et al., 2014). Based on these studies, we have been able to identify and study in detail one of these lineages, which we call here the "Ronnbergia Alliance." This study, therefore, aims to contribute to the understanding of the phylogeny and evolution of the Core Bromelioideae, which is an important step towards the revision of generic concepts within this bromeliad group.

Our prior definition of the Ronnbergia Alliance is based on a consensus of previous phylogenetic studies that show a small and well supported clade, frequently sister to the remaining Core Bromelioideae, that contains representative species of three taxonomic groups Ronnbergia, Hohenbergia subgenus Wittmackiopsis, and the Aechmea lingulata complex (sensu Siqueira Filho and Leme, 2006). Furthermore, it contains allied species of Aechmea subgenus Chevaliera and Aechmea subgenus Pothuava endemic to the rainforests of northwestern South America and southern Central America (AguirreSantoro et al., 2015; Givnish et al., 2011; Maia et al., 2012; Sass and Specht, 2010; Schulte et al., 2009, 2005; Schulte and Zizka, 2008; Silvestro et al., 2014; Fig. 1). Except for the widespread species Aechmea lingulata, these taxonomic groups and allied species of Aechmea are characterized by their narrow endemism within three highly biodiverse regions of the Neotropics: 1) the Chocó-Tumbes-Magdalena region; 2) the central and northern Atlantic Forest and adjacent semi-deciduous forests and Caatinga; and 3) the Caribbean section that includes the Greater Antilles (except Hispaniola), the Cayman and 
Providencia islands, and the Yucatán Peninsula. In previous molecular phylogenetic studies, the Ronnbergia Alliance has received little attention and was only represented by few species. Therefore, we aim to assess the monophyly and phylogenetic relationships of the Ronnbergia Alliance by including a broad sampling of species with morphological and/or biogeographical affinities to the three main taxonomic groups and allied species that constitute this lineage.

The species that constitute these three taxonomic groups and allied species share many morphological affinities; yet they have rarely been placed together in taxonomic treatments. This lack of taxonomic recognition is due to the use of traditionally diagnostic characters for generic delimitation in Bromelioideae. For example, species of Ronnbergia and Aechmea subgenus Pothuava that co-occur in the forests of northwestern South America and southern Central America exhibit simple inflorescences, long-tubular subspreading corollas, and similar patterns of corolla coloration. However, these species have long remained in different genera because species of Aechmea subgenus Pothuava have petal appendages whereas those of Ronnbergia lack them. A well-resolved and highly supported phylogenetic reconstruction for the Ronnbergia Alliance will serve as a framework to assess the taxonomic value of morphological characters traditionally used as well as other so far neglected, characters. This is relevant because previous morphology-based phylogenetic analyses have suggested that overlooked characters such as corolla shape, ovary surface, stigma types, pollen ornamentation, and seed structure are good sources of potential diagnostic characters to define clades across Bromelioideae (Almeida et al., 2009; De Sousa et al., 2008; Faria et al., 2004). Moreover, traditional taxonomic characters such as sepal armature, petal appendages, ovule appendages, 
placentation, and pollen aperture should be revisited because they seem to be informative to diagnose major lineages within Bromelioideae but have been rarely explored in a phylogenetic context (Heller et al., 2015; Mez, 1896; Schulte and Zizka, 2008; Smith and Downs, 1979). In the present study, we explore some of these characters using ancestral character state reconstructions in order to reconstruct their evolutionary history and to assess their stability and diagnostic value. This approach will provide insights for future taxonomic restructuring of the Ronnbergia Alliance when a comprehensive phylogeny of the Core Bromelioideae is reconstructed and will also help detect traits that were important for the diversification of its lineages.

Our approach in this study can be summarized as two main objectives: 1) reconstruct the phylogenetic relationships of the Ronnbergia Alliance using multilocus DNA sequence data and a broad species sampling in order to test its monophyly, establish its placement within the Core Bromelioideae and identify its subclades; and 2) explore the taxonomic and evolutionary importance of 13 morphological characters that show potential as diagnostic characters for the Ronnbergia Alliance and its subclades for future taxonomic reorganization of the group. A better understanding of this lineage will also open new perspectives for future evolutionary and biogeographic studies.

\section{Materials and methods}

\subsection{Taxon sampling}

A total of 168 terminals representing 129 species were included for the phylogenetic analyses (Supplementary Table A). Three species of Bromelia were chosen as outgroups because this genus has been identified as one of the early-diverging lineages within Bromelioideae (Evans et al., 2015; Givnish et al., 2011, 2007; Schulte et al., 2009; 
Schulte and Zizka, 2008). In order to elucidate phylogenetic relationships within the Ronnbergia Alliance, we selected 94 terminals to represent 60 species of the three taxonomic groups and allied species of Aechmea expected to compose this lineage: Ronnbergia (12 spp. included, out of 13 spp. described); Hohenbergia subgenus Wittmackiopsis (17 spp. included, out of 19 spp. described); the Aechmea lingulata complex as defined by Siqueira Filho and Leme (2006) (23 spp. included, out of 26 spp. described); Aechmea subgenus Pothuava endemic to the Chocó-Tumbes-Magdalena region (6 spp. included, out 9 spp. described); and Aechmea subgenus Chevaliera endemic to the Chocó-Tumbes-Magdalena region ( 2 spp. included, out of 3 spp. described).

For the other Bromelioideae species, 71 terminals, corresponding to 67 spp., were sampled in order to include 1) the most likely sister lineages of the Core Bromelioideae, and 2) a broad representation of the so far known main lineages within the Core Bromelioideae (Evans et al., 2015; Sass and Specht, 2010; Schulte et al., 2009; Silvestro et al., 2014). For the former, seven terminals (representing 6 spp.) of the genera Acanthostachys, Ananas, Disteganthus, and Orthophytum were sampled; for the latter, sixty-four terminals (61 spp.) were selected to represent the main lineages and genera of the Core Bromelioideae (excluding those putatively in the Ronnbergia Alliance). This sampling includes six species of Aechmea subgenus Chevaliera and three species of Aechmea subgenus Pothuava not expected to be part of the Ronnbergia Alliance based on previous molecular phylogenetic studies (Evans et al., 2015; Sass and Specht, 2010; Schulte et al., 2009, 2005; Schulte and Zizka, 2008). Sequences of several species were 
downloaded from GenBank and are mostly based on the study of Sass \& Specht (2010) (see Supplementary Table A).

\subsection{Sample collection, DNA extraction, amplification, and sequencing}

Most samples were collected from wild plants in the main centers of diversity of the three taxonomic groups and allied species expected to comprise the Ronnbergia Alliance: Jamaica, Puerto Rico, the Yucatan Peninsula in Mexico, Southeastern Brazil, and Colombia (including Providencia Island). Samples that could not be collected in the field were collected ex situ at the Mary Selby Botanical Gardens in Sarasota, Florida and the private collection of Elton Leme in Teresópolis, Brazil (Supplementary Table A). All samples for DNA extraction were obtained from young leaves quickly dried in silica gel, and subsequently stored at $-20^{\circ} \mathrm{C}$. Only one sample of Aechmea lingulata from the Lesser Antilles was obtained from herbarium material given the importance of including a Caribbean representative of this species in the analyses (permission for DNA extraction granted by the Gray Herbarium).

DNA was extracted using the DNeasy kit from Qiagen following the manufacturer's standard procedures. Sequences for six DNA sequence markers were generated in this study, three from the nuclear genome and three from the plastid genome. These molecular markers were previously used in molecular phylogenetic studies of Bromeliaceae, showing good potential for phylogenetic resolution, and not exhibiting detectable problems of paralogy. The nuclear markers correspond to the nuclear ribosomal external transcribed spacer $(E T S)$, the $23^{\text {rd }}$ intron of RNA polymerase beta subunit II ( $r p b 2)$, and the $8^{\text {th }}$ and $10^{\text {th }}$ exons of glyceraldehyde-3-phosphate dehydrogenase $(g 3 p d h)$. The three plastid molecular markers are the matK gene and part 
of the adjacent 3'trnK intron (matK-trnK), the intergenic spacer between rps16 and trnK (rps16-trnK), and the intergenic spacer between $\operatorname{trn} L$ and $\operatorname{trn} F(\operatorname{trn} L-F)$.

All primers, references and temperature profiles for the PCR reactions are described in Supplementary Table B. All PCR reactions were conducted in $15 \mu$ volumes using Eppendorf Mastercycler Pro thermocyclers. The master mix for all reactions contained $0.5 \mu \mathrm{l}$ of template DNA, $0.75 \mu \mathrm{l}$ of each pair of forward and reverse primers $(10 \mu \mathrm{M}), 1.5 \mu \mathrm{l}$ of BSA $(0.25 \mu \mathrm{g} / \mu \mathrm{l}), 7.5 \mu \mathrm{l}$ of GoTaq Green Master Mix (Promega), and $4 \mu \mathrm{l}$ of water. Only the master mix for $\operatorname{trn} L-F$ additionally contained $3 \mu 1$ of Betaine (1 M) and $1 \mu \mathrm{l}$ of water. Final PCR products were sequenced using the Sanger method for DNA sequencing and the same primers of the PCR reactions through the high-throughput service at University of Washington, U.S.A. In order to avoid the limitations of having large amounts of missing data, the final dataset contains only taxa from which sequences of four or more molecular markers were generated. The only exception is the herbarium sample of Aechmea lingulata, from which it was only possible to obtain partial sequences of the plastid markers.

\subsection{Sequence alignment and phylogenetic analyses}

Edition of sequences and generation of contigs were conducted in Sequencher version 5.2.4 (Gen Codes Corp. Ann Arbor, MI, USA). The alignments for each individual marker were performed online with MAFFT version 7 (Katoh and Standley, 2013), using the global homology option and default parameters. These alignments were subsequently inspected in Mesquite version 3.01 (Maddison and Maddison, 2014) for obvious misalignments of large blocks, which were manually adjusted when strictly necessary. The summary of alignment statistics was calculated for each alignment using 
the $R$ packages Ape and Phangorn (Paradis et al., 2004; R Development Core Team, 2015; Schliep, 2011).

The best-fit substitution model of nucleotide evolution was determined for each DNA sequence region using jModelTest (Darriba et al., 2012; Guindon and Gascuel, 2003). A neighbor-joining tree was used to compute the likelihood scores of the data across different models of substitution. Subsequently, the best model for each partition was chosen using the corrected Akaike Information Criterion (AICc). The substitution model GTR $+\Gamma$ was selected for $E T S, g 3 p d h$, and $m a t K-\operatorname{trnK}$; the model GTR $+\Gamma+\mathrm{I}$ was chosen for $r p s 16-\operatorname{trnK}$ and $\operatorname{trnL}-F$; and the model $\mathrm{HKY}+\Gamma$ was specified for $r p b 2$.

In addition to the alignments of each of the individual markers, three concatenated datasets were generated for the analyses: one combining the three plastid markers (cpDNA); one combining the three nuclear markers (nrDNA); and one combining all markers together (combined matrix). These matrices were generated with the program 2matrix (Salinas and Little, 2014), which constructs concatenated datasets and automatically generates files for further phylogenetic analyses. For each concatenated dataset, independent phylogenetic analyses using three different approaches were conducted: Maximum Parsimony (MP), Maximum Likelihood (ML), and Bayesian Inference (BI). Only ML analyses were performed for the alignments of the individual molecular markers in order to visually detect incongruences.

Maximum Parsimony analyses were executed with the program TNT (Goloboff et al., 2008). Heuristic searches were conducted using ten replicates of ratchet coupled with tree-drifting, and a final round of tree bisection and reconnection (TBR) First, for each of 200 ratchet iterations, a random set of characters was upweighted and downweighted ten 
magnitudes. One optimal tree was searched and saved using the reweighted matrix and TBR as a tree perturbation strategy. After setting the matrix to its original weights, a new optimal tree was searched with TBR using the saved tree from the previous phase.

Second, tree-drifting was conducted for 200 iterations using the saved trees of the ratchet phase. This method is similar to the ratchet, but instead of reweighting a random set of characters, it saves optimal or suboptimal trees per iteration based on the values of the Raw Length Difference and Relative Fit Difference metrics described by Goloboff (1999). The final set of trees obtained from the ratchet plus tree-drifting searches were subsequently used for a final heuristic search using TBR to completion, saving a maximum of 10,000 trees. A strict consensus tree was generated from the final set of most parsimonious trees. Nodal support was estimated using 1000 bootstrap replicates (BS) with similar parameters of the initial ratchet search but using only 20 iterations per pseudoreplicate.

Maximum Likelihood analyses were performed with the program $R A x M L$ Blackbox (Stamatakis, 2014) through the Cipres Science Gateway service (Miller et al., 2011). The GTRGAMMA model of evolution was independently specified for each partition. Nodal support was estimated using 300 bootstrap replicates through the "rapid bootstrapping" option of $R A x M L$.

Bayesian Inference analyses were conducted with MrBayes 3.2.3 (Ronquist et al., 2012) through the Cipres Science Gateway service (Miller et al., 2011), and the high performance computer cluster of the New York Botanical Garden. The models of evolution selected by jModelTest were set for each independent partition. Default priors of model parameters were also defined for each partition. Two parallel MCMC runs of 
$30,000,000$ generations were conducted, each run containing three heated chains and one cold chain. The default value of temperature coefficient was used for all analyses. Trees and estimated parameter values were sampled every 1000 generations, thus obtaining a total of 30,000 samples from which the first 7500 were discarded as burn-in.

Convergence between the two independent runs and inspection of appropriate parameter mixing was assessed with Tracer version 1.5 (Rambaut and Drummond, 2003). A $50 \%$ majority-rule consensus tree, with mean branch lengths, and posterior probabilities of clades (PP) was generated to summarize the results of the post burn-in posterior distribution of trees.

\subsection{Congruence}

In order to identify major disagreements among the phylogenetic hypotheses generated with the separate datasets, pairwise comparisons of well-supported incongruent clades were performed (Mason-Gamer and Kellogg, 1996). Topological conflicts were considered significant if the same set of taxa showed two different relationships supported with $\mathrm{BS}$ values of $75 \%$ or more and $\mathrm{PP} \geq 0.95$. A lack of well-supported conflict among datasets is a good indication for combining all genes in a concatenated phylogenetic analysis.

To further explore incongruence, a primary concordance tree was constructed through a Bayesian Concordance Analysis (BCA) with the program Bucky version 1.4.3. (Ané et al., 2007; Larget et al., 2010). This method explores and integrates the posterior distribution of trees obtained through Bayesian Inference analyses of the individual partitions without making assumptions on the causes for gene incongruence (e.g. incomplete lineage sorting, hybridization, paralogy, sequencing error, etc.). The primary 
concordance tree summarizes the clades with the largest concordance factors, thus, providing an estimate of the dominant vertical phylogenetic signal among genes. A comparison of incongruent clades between the primary concordance tree and the combined tree provides further evidence for problematic results. For this analysis, a new round of MrBayes analyses was performed for each individual partition but including only taxa without missing any of the molecular markers. The three plastid markers were treated as a single partition. The posterior distributions of trees from each MrBayes analysis were used as input for Bucky. The primary concordance tree was obtained by conducting two MCMC runs of 1 million generations, using a discordance parameter alpha value of 1 and a burn-in of 100,000 samples.

\subsection{Phylogenetic hypothesis testing}

The widespread species, Aechmea lingulata, is expected to be closely related to the Brazilian-centered species of the Aechmea lingulata complex; however, the presence of this species in the Caribbean may mean that it is actually more closely related to the Caribbean species of the Ronnbergia Alliance. Therefore, the Approximately Unbiased test of phylogenetic tree selection (AU test; Shimodaira, 2002) was used for testing whether Aechmea lingulata could be nested with or within the Caribbean species of the Ronnbergia Alliance. In order to obtain sitewise log-likelihood values for this alternative hypothesis of monophyly, Maximum Likelihood analyses were conducted with $R A x M L$ Blackbox (Stamatakis, 2014) using the concatenated dataset and the same parameters of the original ML analyses but constraining the topologies accordingly. The AU test was conducted with the program CONSEL (Shimodaira and Hasegawa, 2001), which uses the sitewise log-likelihood values from the empirical and constrained ML analyses as input. 
$P$-values below 0.05 indicate that the hypothesis of monophyly is not supported by the data.

\subsection{Morphological character data}

A morphological study was conducted in order to identify potential characters for circumscribing the Ronnbergia Alliance and its main subclades. Morphological data were obtained from examination of herbarium material, liquid-preserved collections, photographs, literature, and living plants when possible. The first author determined all the examined specimens, most of them corresponding to the same terminals used for the phylogenetic analyses. A final set of 13 characters, nine of which were discrete and four were continuous, was selected for further analysis because of their relative stability within clades (Table 1).

The list of discrete characters is the following: Character 1: pseudopetiole (0) present and (1) absent. Pseudopetiole refers to the abrupt narrowing of the leaf blades above the sheaths. Character 2: inflorescence ramification (0) simple (not branched) or (1) paniculate (branched). Character 3: dorsoventral floral compression (0) terete or (1) compressed. Character 4: corolla apex (0) reflexed, (1) erect, or (2) cucullate. Character 5: petal apex (0) acuminate to acute or (1) obtuse to retuse. Character 6: petal color (0) pigmented, other than white, or (1) white. Character 7: petal appendages (0) absent or (1) present. Petal appendages correspond to two laminar structures of variable morphology that originate at the base of the adaxial surface of the petal, prolonging parallel to the sides of the antipetalous filaments, and that are detached from the petals apically. Character 8: filament apex (0) much narrower than the anthers or (1) as wide as the anthers. Character 9: chalazal ovule appendage: (0) absent to rudimentary 
or (1) present (long-appendaged). This character corresponds to the prolongation of the raphe above the chalaza and seems to be important for seed attachment to tree barks and rocks (Benzing, 2000). Only two character states were considered here in order to explore the importance of this character to separate large groups in Bromelioideae; however, the wide variation in longitude of these appendages should be further explored in future taxonomic studies.

Continuous characters were measured on one to five specimens per species, depending on material availability. The measurements used in the analyses correspond to the log-transformed mean values of the following characters: Character 10: flower length. Character 11: corolla tube to flower length ratio. Character 12: sepal connation to flower length ratio. Character 13: sepal mucro length to flower length ratio.

\subsection{Ancestral character state reconstructions}

Ancestral character state reconstructions were conducted for the 13 surveyed characters on a subsampled phylogeny of the Ronnbergia Alliance. In order to take phylogenetic uncertainty into account for the ancestral character state reconstructions, a random subset of 1000 trees was selected from the post burn-in posterior distribution of trees from the MrBayes analysis of the combined dataset. Subsequently, all the trees were pruned conserving the tree original branch lengths in order to obtain the following subset of taxa: 1) all the species of the Ronnbergia Alliance; 2) ten representatives of the sister group of the Ronnbergia Alliance (Aechmea blumenavii, A. bromeliifolia, A. contracta, A. dactylina, A. mariae-reginae, Aechmea nudicaulis, Hohenbergia andina, H. correiaaraujoi, Lymania spiculata, and Ursulea tuitensis); and 3) three representatives of the possible sister groups of the Core Bromelioideae (Acanthostachys strobilacea, Ananas 
comosus, and Disteganthus morii). These species were selected in order to include an estimation of the morphological diversity outside the Ronnbergia Alliance. Within the Ronnbergia Alliance, duplicate accessions per species that formed monophyletic groups were also pruned, giving priority to field-collected individuals and/or type specimens. For those samples of the same species not resolved as monophyletic, the accessions were conserved and scored independently in the morphological survey.

Two methods of ancestral state reconstruction were used for the discrete characters in order to consider possible incongruences between them: Maximum Likelihood ancestral character state reconstruction (ML-ASR) and Bayesian ancestral character state reconstruction (BI-ASR). Maximum Likelihood ancestral state reconstructions were performed on the 1000 trees for all discrete characters fitting onerate model and two-rate models of character evolution in BayesTraits version 2.0 (Meade and Pagel, 2014). A two-rate model was chosen as the best-fit model for all binary characters based on the likelihood ratio test. The model for character 4 , the only multistate character, corresponds to a six-rate model. Bayesian ancestral reconstructions were also conducted in BayesTraits version 2.0 using the options MultiState and MCMC. Reverse Jump MCMC was performed in order to integrate over the space of parameters across different models of evolution. An exponential prior distribution was chosen for the analyses. Because little is known about the mean values of the exponential prior distribution, this parameter was seeded from a uniform hyper-prior. The approximate interval of this hyper-prior was estimated from the empirical values of rate change obtained from the ML-ASR analyses for each character. For each character reconstruction, two MCMC runs were conducted for 10 million generations, sampling 
every 10,000 generations, and setting a burn-in of 100,000 generations. The mean values of the ML-ASR and BI-ASR probabilities were calculated for the better-supported selected nodes of the phylogeny. The corresponding values for these nodes across the 1000 trees were summarized with the option addMRCA. The final results of the ML-ASR and BI-ASR were plotted on the $50 \%$ majority rule consensus tree of the combined MrBayes analysis.

Ancestral maximum likelihood reconstruction of the continuous characters was conducted with the function ContMap from the $R$ package Phytools (R Development Core Team, 2015; Revell, 2012) using a Brownian model of trait evolution to estimate ancestral values in the internal nodes of the phylogeny. These reconstructions were mapped on the best tree of the combined ML analysis, which was transformed to ultrametric using the function chronopl from the $R$ package Ape (Paradis et al., 2004; R Development Core Team, 2015), with a lambda value of 0.1 . This function uses the semiparametric smoothing, penalized likelihood method described by Sanderson (2002).

\section{Results}

3.1. Phylogenetic analysis of the individual markers, cpDNA and nrDNA datasets, and congruence

Table 2 shows the general statistics of the alignments for the individual and combined datasets. The nuclear markers exhibited the greatest amount of variable and parsimony-informative sites. ETS was the most informative region among all the individual markers. In contrast, the plastid markers showed lower percentages of variable 
and parsimony-informative characters, matK-trnK being the most variable of the plastid markers.

The ML analyses of the individual markers resulted in topologies with different degrees of resolution and support (trees not shown). No significant incongruences were detected among the topologies; most of the conflict corresponds to shallow clades with low BS support values. Except for ETS, none of the individual analyses recovered the monophyly of the Ronnbergia Alliance; however, the topologies obtained with each marker tended to group the species of the Ronnbergia Alliance in medium to low supported clades.

The combined plastid molecular markers produced a phylogenetic hypothesis with higher resolution and support than any of the individual markers alone (Fig. 2). Phylogenetic analyses using MP, ML, and BI showed highly congruent topologies that differed in the degree of resolution for some clades and did not produce well-supported incongruent clades among them (MP and ML trees not shown). The phylogenetic analyses of the cpDNA dataset alone did not provide enough information to resolve the monophyly of the Ronnbergia Alliance. The $50 \%$ majority rule consensus tree of the BI analysis showed that the backbone topology is a polytomy formed by seven lineages, from which all the species of the Ronnbergia Alliance encompassed two of the three largest clades (Fig. 2). The first of these two clades received medium to high statistical support (BS 94/68, PP 0.82), and was composed exclusively by species endemic to the Chocó-Tumbes-Magdalena region of Aechmea subgenus Chevaliera, Aechmea subgenus Pothuava and Ronnbergia. The second clade was highly supported (BS 100/94, PP 1) and contained all the species of the Ronnbergia Alliance endemic to Eastern Brazil and the 
Caribbean, in addition to the widespread Aechmea lingulata. Within this clade, the species of the Caribbean-endemic Hohenbergia subgenus Wittmackiopsis formed a medium to well-supported monophyletic group (BS 100/76, PP 0.98).

The phylogenetic analyses of the three nuclear molecular markers produced medium to well supported and more resolved overall topologies, especially at the deeper nodes (Fig. 2). No major conflicts were detected among the MP, ML and BI analyses, although the MP consensus tree showed more polytomies (MP and ML trees not shown). The 50\% majority rule consensus tree of the BI analysis showed the Ronnbergia Alliance as monophyletic with high values of nodal support (BS 93/98; PP 0.99). This clade was nested within a low to highly supported clade (BS -/51, PP 1) that also contained a lineage comprised by the remaining tank-forming species of the Core Bromelioideae, excluding six species of Aechmea subgenus Chevaliera. Like in the cpDNA analyses, the species in the Ronnbergia Alliance were grouped in the same two low to highly supported clades (BS -/58, PP 1; and BS -/75, PP 0.99). The monophyly of the Caribbean-endemic Hohenbergia subgenus Wittmackiopsis was also supported by the nrDNA dataset (BS 72/85, PP 1).

The main differences between the phylogenetic hypotheses obtained with the cpDNA and nrDNA datasets were mostly associated to the level of resolution. The cpDNA dataset produced a polytomic backbone topology whereas the nrDNA analyses resolved basal relationships of the phylogeny with low to medium support values. Although the polytomy obtained with the cpDNA analysis did not provide information about the monophyly of the Ronnbergia Alliance, it also did not represent a conflicting scenario for this hypothesis. Both analyses supported the same main clades across the 
phylogeny and exhibited relatively low resolution within these clades. No well-supported incongruent clades were detected among the topologies generated with these datasets.

\subsection{Phylogenetic analysis of the combined dataset and primary concordance tree}

The high level of congruence between the single marker phylogenies and the lack of incongruences with high levels of support allowed for the combination of all the markers. The MP, ML and BI analyses conducted with the combined dataset resulted in more resolved topologies compared to those of the individual markers, cpDNA, and nrDNA datasets alone (Fig. 3, Supplementary Figs. A-B).

Figure 3 illustrates the main results of the combined phylogenetic analyses represented on the $50 \%$ majority rule consensus tree of the BI analysis. Here, the species of the Core Bromelioideae formed a low to highly supported clade (BS 42/66, PP 1). This clade excluded several species of Aechmea subgenus Chevaliera, which appeared at the early-diverging branches of the tree, as well as Acanthostachys, Ananas, Disteganthus, and Orthophytum. Two highly supported major lineages were identified within the Core Bromelioideae clade. One lineage comprised all the species of the Ronnbergia Alliance, from now on called the "Ronnbergia Alliance Clade" (BS 100/100, PP 1), whereas the second lineage contained the remaining species of the Core Bromelioideae (BS 99/99, PP 1).

The Ronnbergia Alliance Clade was formed by two strongly supported clades with high geographic structure, the "Pacific Clade" (BS 100/100, PP 0.72) and the "Atlantic Clade" (BS 100/100, PP 1). The Pacific Clade contained species of Aechmea and Ronnbergia endemic to the Chocó-Tumbes-Magdalena region. Two subclades were strongly supported within the Pacific Clade, one containing only species of Ronnbergia 
(Clade A; BS 99/99, PP 0.99), and another containing species of both Ronnbergia and Aechmea subgenus Pothuava (Clade B; BS -/95, PP 1). The remaining species in the Pacific Clade formed a polytomy with the two subclades described above. The Atlantic Clade comprised species of Aechmea and Ronnbergia endemic to eastern Brazil, the Caribbean-endemic Hohenbergia subgenus Wittmackiopsis, and the widespread Aechmea lingulata. Within the Atlantic Clade, the two Brazilian species of Ronnbergia were grouped with three species of the Aechmea lingulata complex in a low to medium supported clade (Clade C; BS 44/68, PP 0.88). This clade was sister to a highly supported lineage that contained the bulk of species of the Atlantic Clade (Clade D; BS 100/100, PP 1). Most of Clade D was composed by species of the Brazilian-centered Aechmea lingulata complex, which formed a grade. Nested within Clade D, Hohenbergia subgenus Wittmackiopsis formed a well-supported monophyletic group, here called the "Caribbean Clade" (BS 100/97, PP 1). The Caribbean Clade exhibited two lineages with high nodal support, one containing Hohenbergia antillana from Puerto Rico grouped with two species mostly restricted to the Blue Mountains in Jamaica $(H$. eriostachya and $H$. polycepahala), and another lineage that comprises species endemic to Jamaica, Puerto Rico, Cuba, and the western Caribbean (Yucatán Peninsula, Cayman Islands, and Providencia).

The primary concordance tree exhibited the same main clades of the combined phylogenetic analyses with concordance factors of 0.5 or below (Supplementary Fig. C). The primary concordance tree summarized the overall signal of the individual genes; therefore, its similarity with the combined tree provided further confidence for preferring the combined analyses over the analyses of single markers. 


\subsection{Hypothesis testing}

The AU test produced a $p$-value of 0.04 for the hypothesis where A. lingulata formed a monophyletic group with the Caribbean species of the Ronnbergia Alliance. This result indicates that this was not a competing hypothesis compared to the unconstrained analyses, and cannot be explained by our data.

\subsection{Morphological analysis}

The two methods implemented for ancestral character state reconstruction (ASR) of discrete characters showed similar results across all characters (Figs. 4-9; Supplementary Table C). However, ML-ASR and BI-ASR disagreed on the reconstruction of inflorescence ramification, filament apex, and ovule appendages at the node representing the ancestor of the Core Bromelioideae (node C.B. in Figs. 4-9). This was an expected result as the sampling of the sister clade of the Ronnbergia Alliance and early-diverging Core Bromelioideae was incomplete.

\subsubsection{ASR of characters with diagnostic potential for the Ronnbergia Alliance Clade}

Ancestral character reconstructions for the ancestor of the Ronnbergia Alliance Clade must be interpreted cautiously as the incomplete morphological sampling outside this lineage may have a strong influence in the results. The results presented here, however, can be used as a starting point for a future, more thorough, search of diagnostic characters for the Ronnbergia Alliance Clade.

Corolla apex (character 4). All the species of the Ronnbergia Alliance Clade exhibit corollas with reflexed apices; the only exception is Aechmea bicolor, which has erect apices (Fig. 4). This character is also present in the sister lineage of the Ronnbergia Alliance Clade. The reflexed apex of the corolla was strongly supported as the ancestral 
character for the Ronnbergia Alliance Clade and all its subclades. Chalazal ovule appendages (character 9). The chalazal ovule appendage is absent or rudimentary in all the species of the Ronnbergia Alliance Clade and was reconstructed as the ancestral state for this lineage (Fig 4). The long chalazal appendage appears otherwise only in some species outside the Ronnbergia Alliance Clade.

\subsubsection{ASR of characters with diagnostic potential for the Pacific and Atlantic Clades}

Petal apex (character 5). Obtuse to retuse petals are more common in the species of the Pacific Clade than in the ones of the Atlantic Clade; acuminate to acute petals are more frequent in the latter. The same pattern was observed in the ancestors of these clades. The most likely ancestral state of the Ronnbergia Alliance Clade was obtuse to retuse petals (Fig. 5). Petal color (character 6). Pigmented petals were more common in the Pacific Clade than in the Atlantic Clade (Fig. 5). Ancestral state reconstructions suggested that the ancestor of the Ronnbergia Alliance Clade likely exhibited pigmented flowers. This was also the ancestral character state for the Pacific Clade and six independent transformations to white flowers occurred within this lineage. A transformation to white flowers occurred for the ancestor of the Atlantic Clade followed by fixation of this state across its subclades. Nevertheless, seven cases of independent reversals to colored flowers occurred in this clade.

\subsubsection{ASR of traditional taxonomic characters for diagnosing genera in Bromelioideae}

Inflorescence ramification (character 2). The species of the Pacific Clade always exhibit simple inflorescences, whereas the Atlantic Clade contained species with both simple and paniculate inflorescences (Fig. 6). Simple inflorescences were the most likely state for the ancestor of the Ronnbergia Alliance Clade. This character became fixed in 
the Pacific Clade without further transformations to paniculate inflorescences. The ancestral state of inflorescence ramification was uncertain for the Atlantic Clade. The ancestor of Clade $\mathrm{C}$ exhibited simple inflorescences and experienced one transformation to paniculate inflorescences. Paniculate inflorescences were the most likely ancestral state of Clade D, with seven independent reversals to simple inflorescences across the clade. All the species of the Caribbean Clade exhibit paniculate inflorescences and this also was its most likely ancestral state. Petal appendages (character 7). Most species of the Ronnbergia Alliance Clade lack petal appendages; however, the presence of this character is not rare in the group (Fig. 6). Ancestral reconstructions strongly suggested that the lack of petal appendages was the ancestral state for the Ronnbergia Alliance Clade and most of its lineages. Eight independent acquisitions of petal appendages occurred within this lineage. Presence of petal appendages was reconstructed as the ancestral state for Clade B, followed by one reversal to naked petals.

\subsubsection{ASR of characters with diagnostic potential for specific subclades}

Pseudopetiole (character 1). Pseudopetiolate leaves are present in all the species of clade A and two species within the Atlantic Clade (Fig. 7). It is uncertain if this character arose early in the history of the Ronnbergia Alliance Clade; however, the ancestral reconstructions suggested that the ancestor of the Pacific Clade had this character state. Within this clade, pseudopetiolate leaves became fixed in Clade A and transformed into oblong leaves in the remaining species outside this clade. The Atlantic Clade likely arose from an ancestor with oblong leaves; pseduopetiolate leaves appeared independently twice during the diversification of this lineage. Dorsoventral floral compression (character 3). This character is present in all the species of the Caribbean 
Clade and four species within the Pacific Clade (Fig. 7). The ancestral reconstructions showed that this character state only became fixed in the diversification of the Caribbean Clade and appeared independently three times in the Pacific Clade. Filament apex (character 8). Most species across the phylogeny exhibit filament apices narrower than the anthers (Fig 7). However, ten species of the Pacific Clade and two species outside the Ronnbergia Alliance Clade have filament apices as wide as the anther. The filament apex as wide as the anther was reconstructed as the most likely ancestral state of the Ronnbergia Alliance Clade and the Pacific Clade. Seven transformations from wide to narrow filament apices occurred during the diversification of the Ronnbergia Alliance Clade. Narrow filaments appeared as the ancestral state of the Atlantic Clade, followed by fixation of this character state along the evolutionary history of this lineage. Transformations into narrow filament apices in the Pacific Clade occurred in the ancestor of Clade B and five independent times in Clade A.

\subsubsection{Continuous characters}

The ancestral reconstruction of continuous characters revealed four general patterns. First, the ancestor of the Pacific Clade likely had longer flowers than the ancestor of the Atlantic Clade (Fig. 8). Second, the ancestors of both Clade A and Clade B exhibited longer corolla tubes in proportion to flower length compared to other lineages (Fig. 8). Third, Clade A and Clade C likely arose from an ancestor with highly connate sepals in relation to flower length (Fig. 9). Finally, the ancestors of both the Atlantic Clade and clade B had longer sepal mucros in proportion to flower length compared to other lineages (Fig. 9).

\section{Discussion}




\subsection{Monophyly, phylogenetic position, and diagnosis of the Ronnbergia Alliance}

Although most of the independent molecular markers and the cpDNA dataset did not provide enough information to resolve the monophyly Ronnbergia Alliance, they did not offer a conflicting scenario against this hypothesis. This lack of resolution was the result of the low variation across the molecular markers, especially those of the plastid genome (Table 2), a phenomenon already discussed in previous molecular phylogenetic studies of Bromelioideae (Evans et al., 2015; Horres et al., 2007; Sass and Specht, 2010; Schulte et al., 2009, 2005; Schulte and Zizka, 2008). Some of these studies suggested that to overcome these limitations it would be important to increase the number of molecular markers and include both nuclear and plastid DNA sequences (Sass and Specht, 2010; Schulte et al., 2009; Silvestro et al., 2014). This observation was confirmed by our study, as the nrDNA dataset alone provided sufficient information to support the monophyly of the Ronnbergia Alliance with medium to high levels of support. Moreover, combining this dataset with the cpDNA alignment further increased the support and resolution of the phylogenetic reconstructions, and clarified the phylogenetic position and relationships within the Ronnbergia Alliance Clade.

The Ronnbergia Alliance was represented in earlier studies by only two or three species that included Aechmea drakeana, A. lingulata, Hohenbergia eriostachya, and Ronnbergia petersii (Givnish et al., 2011; Horres et al., 2007; Schulte et al., 2009; Schulte and Zizka, 2008). Sass and Specht (2010) placed 16 species in this clade but did not have sufficient information to resolve their internal relationships. In contrast, our broad taxonomic sampling allowed placing with confidence 60 species in the Ronnbergia Alliance. Moreover, this large species representation in combination with our DNA 
sequence sampling contributed to increase the resolution of the relationships within the group compared to other studies.

Although our results are not categorically contradicted by other studies, three recent studies did not find support for the monophyly of the Ronnbergia Alliance. In the first study, Silvestro et al. (2014) placed eight species of the Ronnbergia Alliance in a clade that also included Hohenbergiopsis guatemalensis and Billbergia tweediana. Moreover, a ninth species, Aechmea turbinocalyx, was placed in a distant clade with other species of Aechmea and Quesnelia. Because they only used one nuclear marker $(P h y C)$, they did not provide the topologies produced by the cpDNA dataset alone, and their samples were mostly collected from cultivated plants in botanical gardens, it is difficult to discuss the causes of this conflict. In the second study, Evans et al. (2015) included eight species of the Ronnbergia Alliance that appeared grouped in two medium supported clades; these lineages correspond to the Pacific and Atlantic Clades of our analyses. Despite this result, the molecular dataset used in this study did not provide sufficient resolution to reconstruct the monophyly of the Ronnbergia Alliance Clade. Lastly, Aguirre-Santoro et al. (2015) included 20 species of the Ronnbergia Alliance. Despite their relatively large species sampling, their combined morphological and molecular dataset of plastid DNA markers lacked power to resolve the monophyly of the group. However, they recovered three polytomic clades composed exclusively by species of the Ronnbergia Alliance.

The monophyly of the Ronnbergia Alliance highlights the problems with generic delimitation across Bromelioideae. The Ronnbergia Alliance includes fragments of the genera Aechmea and Hohenbergia, and shows the polyphyly of Ronnbergia. From the 
three taxonomic groups and allied species expected to comprise the Ronnbergia Alliance sampled here, only the two species of Aechmea subgenus Chevaliera, and the Caribbeanendemic Hohenbergia subgenus Wittmackiopsis formed monophyletic groups. The remaining species of Aechmea were scattered and intermingled with species of Ronnbergia (Fig. 3). The polyphyly of Ronnbergia had already been discussed by Aguirre-Santoro et al. (2015) and Evans et al. (2015), whereas the polyphyly of Hohenbergia, Aechmea subgenus Pothuava and Aechmea subgenus Chevaliera was mentioned in the studies of Faria et al. (2004), Schulte and Zizka (2008), Sass and Specht (2010), and Evans et al. (2015). In the case of the Aechmea lingulata complex, our results strongly suggest that this is not a monophyletic group. However, Siqueira Filho and Leme (2006) were correct in predicting that the species of this complex were very closely related.

Our combined analyses agree with previous phylogenetic studies by showing the Ronnbergia Alliance Clade as one of the two main lineages of the Core Bromelioideae (Fig. 3). Although the Core Bromelioideae has not been formally circumscribed, most studies recognized this group as the most diverse clade of Bromelioideae. It has been suggested that this lineage experienced an exceptional diversification because of the acquisition of two key adaptations: the epiphytic habit and the formation of tank rosettes (Givnish et al., 2014; Schulte et al., 2009; Silvestro et al., 2014). The Ronnbergia Alliance Clade fits within this radiation because it includes several epiphytic and tankforming species; however, reversions to terrestrial habitats and lack of tanks also occurred in the group (e.g. the terrestrial Aechmea lingulatoides and the tankless Ronnbergia killipiana). There was not a single character that helped unambiguously 
diagnose the Ronnbergia Alliance Clade in our study; however, the morphological ancestral reconstructions suggested that characters such as the reflexed corolla apex and the lack of chalazal ovule appendages are traits that appeared in the ancestor of this lineage and became fixed along the history of the group (Fig. 4).

4.2 Phylogenetic relationships within the Ronnbergia Alliance Clade and diagnostic characters

One of the main results of the present study was that the relationships of the main lineages within the Ronnbergia Alliance Clade showed a high level of resolution and support. Two major well-supported clades were identified within the Ronnbergia Alliance Clade: the Pacific Clade and the Atlantic Clade (Fig. 3). These clades received this labels to illustrate the distinctive geographic disjunction and internal geographic structure of their species composition. Both clades were recovered independently by the cpDNA and nrDNA datasets (Fig. 2) but received better resolution and support in the combined analyses.

\subsubsection{Pacific Clade}

All the species in the Pacific Clade are endemic to the Chocó-Tumbes-Magdalena region. They are currently placed in Aechmea subgenus Chevaliera, Aechmea subgenus Pothuava, and Ronnbergia. Apart from recent phylogenetic studies, the close affinity between species of Aechmea subgenus Pothuava and Ronnbergia had already been detected in taxonomic treatments. For instance, these two groups can only be differentiated by the presence or absence of petal appendages; for this reason, Smith and Downs (1979) included Ronnbergia within the taxonomic key of Aechmea subgenus Pothuava as these two groups are difficult to differentiate when petal characters are not 
available. Moreover, in the absence of petal characters, $R$. petersii looks so similar to the sympatric $A$. allenii that recent taxonomic treatments proposed them as synonyms (Davidse et al., 1995). Despite the importance of petal appendages in taxonomic treatments, our results did not support the use of this character as diagnostic for any group. Nevertheless, we recognized that the absence of petal appendages was the ancestral and most common state across the Ronnbergia Alliance Clade and its main lineages. The presence of petal appendages appeared repeatedly during the diversification of the group and can be useful to separate species or small species complexes (Fig. 6).

The morphological survey of the species in the Pacific Clade did not permit identifying exclusive diagnostic characters that separate this lineage from the Atlantic Clade. However, ancestral reconstructions indicated that the combination of characters that support this group were the presence of simple inflorescences, long flowers, sepals exhibiting short mucro length to flower length ratios, and colored petals with obtuse to retuse apices. Transformations of all these characters were observed within the Pacific Clade but corresponded to isolated, independent events (Figs. 5-6 and 8-9). The presence of pseudopetiolate leaves and filament apices as wide as the anther were reconstructed as ancestral states of the Pacific Clade; however, these characters only became fixed in the strongly supported Clade A, which contains the bulk of species of Ronnbergia, including the type species of the genus, $R$. morreniana (Fig. 7). These characters, combined with long sepal connation in relation to flower length, made Clade A the only clearly diagnosable lineage within the Pacific Clade.

The most dissimilar species in the Pacific Clade corresponded to the members of Aechmea subgenus Chevaliera from the forests of southern Costa Rica to northwestern 
South America: A. germinyana and A. veitchii. In our analyses, they appeared as sister species but their phylogenetic position in the Pacific Clade was unresolved. These species fitted within the Pacific Clade because of their simple inflorescences, subreflexed apices of the corollas, shorter sepal mucros in relation to sepal length, and rudimentary chalazal ovule appendages. Nevertheless, they also exhibited unusual characters within this lineage such as short, compressed flowers, and white petals with acute apices. From a traditional taxonomic point of view, these species are also oddly placed in Aechmea subgenus Chevaliera because of their tank-forming rosettes, short subspreading flowers, well-developed petal appendages, and rudimentary chalazal appendages, characters mostly absent in the remaining species of this subgenus. The geographic distribution of these species in the same geographic range of the other species in the Pacific Clade further supported their inclusion within this lineage.

\subsubsection{Atlantic Clade}

The Atlantic Clade is the largest lineage within the Ronnbergia Alliance Clade (Fig. 3). Like in the Pacific Clade, the species within the Atlantic Clade also exhibit very restricted patterns of geographic distribution with most of the species being endemic to eastern Brazil and the Caribbean. This clade also includes Aechmea lingulata, which is mostly distributed through the Atlantic coast of the Neotropics and the Caribbean, from northeastern Brazil to the Caribbean. Ancestral character reconstructions suggested that the ancestor of the Atlantic Clade differed from that of the Pacific Clade by their paniculate inflorescences, shorter flowers, sepals exhibiting long mucro length to sepal length ratios, and white petals with acuminate to acute apices (Figs. 5-6 and 8-9). 
Within the Atlantic Clade, the Aechmea lingulata complex was polyphyletic and intermingled with the Brazilian species of Ronnbergia. This was not an unexpected result as recent taxonomic studies have emphasized that using the lack of petal appendages to describe species of Ronnbergia in Brazil should be avoided; instead, these species should be placed in the Brazilian-centered Aechmea lingulata complex (e.g. Leme and Kollmann, 2011; Siqueira Filho and Leme, 2006). Our results permitted identifying two main lineages within the Atlantic Clade: Clade $\mathrm{C}$ and Clade $\mathrm{D}$. Clade $\mathrm{C}$ was a medium to low-supported clade composed by five species of Aechmea and Ronnbergia endemic to the Central Atlantic Forest. No diagnostic morphological characters were found to support this clade; however, character reconstructions suggested that the ancestor of this group likely exhibited simple inflorescences, long flowers, shortly to medium exposed corolla tubes in relation to flower length, and long connation of sepals in relation to flower length (Figs. 6 and 8-9). Clade D, on the other hand, was strongly supported and comprised of the remaining species of the Aechmea linguata complex and the Caribbean Clade. This lineage mostly contained species with paniculate inflorescences; short flowers; long sepal mucros in relation to flower length; corolla tubes shortly exposed; and white flowers (Figs. 5-6 and 8-9). The relationships among the species of the Aechmea lingulata complex were mostly unresolved in a polytomy that also included a medium supported clade that comprises A. bicolor as sister to the Caribbean Clade. The widespread Aechmea lingulata was related to other Brazilian-endemic species of Aechmea and did not seem to be directly related to the Caribbean Clade. This pattern was further supported by the AU test, which rejected a scenario where A. lingulata formed a monophyletic group with the Caribbean Clade. 


\subsubsection{Caribbean Clade}

Both the combined and independent datasets strongly supported the monophyly of the Caribbean Clade; a lineage entirely formed by all the species of Hohenbergia subgenus Wittmackiopsis (Figs. 2-3). Our analyses suggested that this clade can be

diagnosed within the Ronnbergia Alliance Clade by its strongly compressed flowers. This character was not exclusive of the Caribbean Clade, as it also appeared once within the Pacific Clade and outside the Ronnbergia Alliance Clade (Fig. 7). The Caribbean Clade also conserved the diagnostic characters of Clade D: paniculate inflorescences, long sepal mucros in relation to flower length, short exposition of the corolla tube to flower length ratio, and white petals (except for three species that exhibit green petals), which allowed its easy recognition (Figs. 5-6 and 8-9). In taxonomic classifications, the combination of some of these characters, such as the presence of paniculate inflorescences, strongly compressed flowers forming strobilate spikes, and presence of petal appendages, corresponds to the current diagnosis of the genus Hohenbergia (Smith and Downs, 1979). However, our results highlighted that the lack of ovule appendages and the presence of white (rarely green) petals were more important diagnostic characters to place Hohenbergia subgenus Wittmackiopsis within the Ronnbergia Alliance rather than closely related to the remaining species of Hohenbergia, all of them grouped in Hohenbergia subgenus Hohenbergia. Moreover, the diagnostic value of the presence of petal appendages was not supported by our data, as the ancestral state of the Caribbean Clade was the absence of these structures (Fig. 6).

The close relationship of the Caribbean Clade with a grade of species mostly endemic to eastern Brazil revealed a major disjunction within the Ronnbergia Alliance. 
As discussed above, only the range of Aechmea lingulata overlaps with these two areas of geographic distribution; however, a close relationship between this species and the Caribbean Clade was not supported by our data. This pattern suggests that the diversification of the Caribbean Clade likely corresponded to an event of long-distance dispersal.

\subsection{Trends in biogeography and morphological evolution}

The Ronnbergia Alliance is part of the Core Bromelioideae, one of the most recent adaptive radiations in Bromeliaceae. This diversification has been suggested to be triggered by the combined acquisition of CAM photosynthesis, epiphytic habit, tankforming rosettes, and the production of large numbers of small, appendaged seeds, which increased ecological opportunity and permitted the colonization of unexploited niches (Givnish et al., 2014; Quezada and Gianoli, 2011; Silvestro et al., 2014). Other characters such as the acquisition of asymmetrical sepals are also associated to the diversification of this group but have received less attention (Schulte and Zizka, 2008). Because they make part of the Core Bromelioideae radiation, the members of the Ronnbergia Alliance Clade also exhibit these characters; however, this group contains cases of reversal to $\mathrm{C} 3$ photosynthesis, terrestrial habit, and lack of tank-forming rosettes (Crayn, 2004; Silvestro et al., 2014; Smith and Downs, 1979). This phenotypic plasticity indicates that instances of adaptive diversification are common in this group and respond to colonization of ecosystems that range from super-humid forests in the Chocó region to dry Caatingas in eastern Brazil. Our analyses identified two characters that remain unchanged within the Ronnbergia Alliance Clade: tubular corollas with reflexed apices and lack of chalazal ovule appendages (Fig. 4). The functionality of these floral characters has not been 
formally studied in Bromeliaceae; however, chalazal ovule appendages have been described to remain present in the seeds in order to favor adhesion to animals for dispersal or surfaces such as tree barks for establishment of seedlings (Benzing, 2000; Givnish et al., 2014). Perhaps the absence of these structures in the Ronnbergia Alliance explains why the species have such narrow ranges of geographic distribution and can only grow as terrestrials, rupicolous or epiphytes in the lower strata of the forest.

Another remarkable result evidenced in the present study was the clear geographical separation of the main lineages in the Ronnbergia Alliance Clade. The phylogenetic hypotheses suggested two major disjunctions. The first disjunction occurred early in the history of the group, separating the Pacific and Atlantic Clades between northwestern South America and eastern Brazil. The second disjunction occurred later in the diversification of the Atlantic Clade, separating the Brazilian species from the Caribbean Clade. Although our analyses provided evidence for the occurrence of these disjunctions, only a future biogeographic approach can provide appropriate hypotheses to explain the causes and sequence of these events (Aguirre-Santoro in preparation).

Our analyses suggested that the characters that exhibited major transformations after the early split of the Pacific and Atlantic Clades were inflorescence ramification, floral size, sepal mucro size in relation to flower length, petal color, and petal apex. Assuming adaptive evolution, these shifts in reproductive characters indicate that both lineages diversified under different influence of pollinators, herbivores, and fruit dispersers. In the case of the Brazilian-Caribbean disjunction, the most extreme character transformation was related to the compression of flowers in the Caribbean Clade (Fig. 7). All the species in the Caribbean Clade exhibited strobilate spikes that contain flowers 
with different levels of compression, frequently protected by large and/or spiny floral bracts. On the other hand, the Brazilian species exhibited lax to sublax spikes with terete flowers and short floral bracts, either spiny or smooth. The causes that led to floral compression have not yet been studied in Bromeliaceae; however, this pattern suggests that the diversification in the Caribbean islands favored floral compression in combination with floral bract protection and development of sepal mucros, characters that contribute to restrict access to flower herbivores or undesired fruit dispersers.

Another likely case of diversification associated to character changes occurred in Clade A within the Pacific Clade (Figs. 3 and 7). Our results showed that the origin of this group was associated with the presence of pseudopetiolate leaves, the complete lack of petal appendages, and two characters not studied here: the lack of leaf margin serration and the presence of explosive berries. It is possible that these traits are associated with the diversification of the group in the understory of highly humid forests of the Chocó region. Explosive dry fruits are relatively common across the Angiosperms; nevertheless, explosive berries are very rare characters. In Bromeliaceae, this mechanism of seed dispersal has only been reported in Ronnbergia; however, it has been poorly documented in general and needs further understanding.

\section{Conclusions}

Our comprehensive taxonomic sampling and use of six DNA sequence markers provided evidence to support the monophyly of the Ronnbergia Alliance, reveal the relationships within this clade, and explore the importance of selected morphological characters. These strongly supported results will serve as framework for future studies 
focused on proposing a stable and predictive classification of genera within the conflictive Core Bromelioideae. Moreover, the phylogenetic hypotheses showed that the diversification of the Ronnbergia Alliance clade was the result of two major geographic disjunctions across the neotropics. These disjunctions were followed by subsequent, highly localized radiations in three centers of diversity: (1) the Chocó-TumbesMagdalena region; (2) eastern Brazil; and (3) the Caribbean. These results set an ideal scenario for future biogeographic studies that aim to understand the processes that produced this exceptional diversification. Finally, ancestral state reconstructions showed that although the Ronnbergia Alliance is a phenotypically variable lineage, there are characters that became fixed in its major lineages. It is possible that these characters provided adaptive advantages that promoted the diversification of the clades. However, it is necessary to use further morphological and ecological data combined with modern comparative methods to test evolutionary questions associated to trait evolution.

\section{Acknowledgements}

We are thankful to The New York Botanical Garden, CUNY-Graduate Center, COLCIENCIAS, the American Society of Plant Taxonomists, The Explorers Club of America, and The Systematic Association and Linnaean Society of London for providing funds and resources to carry out this project. This research was partially funded by the NSF through grants to FAM (DEB-1343612, DEB-0818399) and Wayt W. Thomas (DEB-0946618). We also thank André Amorim, Eldis Becquer, Julio Betancur, Keron

Campbell, Tracy Commock, Lukas Daneu, Rafaela Forzza, Bruce K. Holst, Lawrence Kelly, Elton Leme, Raquel Monteiro Fernandes, Andreas Oberli, Paola Pedraza, Gregory 
Plunkett, Ivón Ramírez-Morillo, Eugenio Santiago, Matthew Sewell, and Wayt W.

Thomas who directly contributed to the laboratory and field components of this project.

\section{References}

Aguirre-Santoro, J., Betancur, J., Brown, G.K., Evans, T.M., Salgueiro, F., Alves-

Ferreira, M., Wendt, T., 2015. Is Ronnbergia (Bromeliaceae, Bromelioideae) a geographically disjunct genus? Evidence from morphology and plastid DNA sequence data. Phytotaxa 219.3, 261-275.

doi:http://dx.doi.org/10.11646/phytotaxa.219.3.6

Almeida, V.R., Ferreira da Costa, A., Mantovani, A., Gonçalves-Esteves, V., de Oliveira, R.C., Forzza, R.C., 2009. Morphological phylogenetics of Quesnelia (Bromeliaceae, Bromelioideae). Syst. Bot. 34, 660-672.

doi:10.1600/036364409790139619

Ané, C., Larget, B., Baum, D.A., Smith, S.D., Rokas, A., 2007. Bayesian estimation of concordance among gene trees. Mol. Biol. Evol. 24, 412-426. doi:10.1093/molbev/ms1170

Barfuss, M.H., Samuel, R., Till, W., Stuessy, T.F., 2005. Phylogenetic relationships in subfamily Tillandsioideae (Bromeliaceae) based on DNA sequence data from seven plastid regions. Am. J. Bot. 92, 337-351. doi:10.3732/ajb.92.2.337

Benzing, D.H., 2000. Bromeliaceae : Profile of an Adaptive Radiation. Cambridge University Press, Cambridge, UK; New York, NY, USA. 
Bouchenak-Khelladi, Y., Onstein, R.E., Xing, Y., Schwery, O., Linder, H.P., 2015. On the complexity of triggering evolutionary radiations. New Phytol. 207, 313-326. doi:10.1111/nph.13331

Brown, G.K., Leme, E.M.C., 2005. The re-establishment of Andrea (Bromeliaceae : Bromelioideae), a monotypic genus from Southeastern Brazil threatened with extinction. Taxon 54, 63-70.

Brown, G.K., Terry, R.G., 1992. Petal Appendages in Bromeliaceae. Am. J. Bot. 79, 1051. doi: $10.2307 / 2444915$

Crayn, D.M., 2004. Multiple origins of crassulacean acid metabolism and the epiphytic habit in the Neotropical family Bromeliaceae. Proc. Natl. Acad. Sci. 101, $3703-$ 3708. doi:10.1073/pnas.0400366101

Darriba, D., Taboada, G.L., Doallo, R., Posada, D., 2012. jModelTest 2: more models, new heuristics and parallel computing. Nat. Methods 9, 772-772. doi:10.1038/nmeth.2109

Davidse, G., Sousa, M., Chater, A., 1995. Flora Mesoamericana, Volume 6: Alismataceae to Cyperaceae. Universidad Autonoma de Mexico, Missouri Botanical Garden, Mexico City, Mexico.

De Sousa, G.M., Wanderley, M.D.G.L., Alves, M., 2008. Inflorescence architecture in Brazilian species of Aechmea subgenus Chevaliera (Bromeliaceae Bromelioideae). Bot. J. Linn. Soc. 158, 584-592. doi:10.1111/j.10958339.2008.00914.x 
Evans, T.M., Jabaily, R.S., de Faria, A.P.G., de Sousa, L. de O.F., Wendt, T., Brown, G.K., 2015. Phylogenetic relationships in Bromeliaceae subfamily Bromelioideae based on Plastid DNA sequence data. Syst. Bot. 40, 116-128. doi:10.1600/036364415X686413

Faria, A.P.G., Wendt, T., Brown, G.K., 2004. Cladistic relationships of Aechmea (Bromeliaceae, Bromelioideae) and allied genera. Ann. Mo. Bot. Gard. 91, 303319.

Givnish, T.J., Barfuss, M.H.J., Ee, B.V., Riina, R., Schulte, K., Horres, R., Gonsiska, P.A., Jabaily, R.S., Crayn, D.M., Smith, J.A.C., Winter, K., Brown, G.K., Evans, T.M., Holst, B.K., Luther, H., Till, W., Zizka, G., Berry, P.E., Sytsma, K.J., 2014. Adaptive radiation, correlated and contingent evolution, and net species diversification in Bromeliaceae. Mol. Phylogenet. Evol. 71, 55-78. doi:10.1016/j.ympev.2013.10.010

Givnish, T.J., Barfuss, M.H.J., Ee, B.V., Riina, R., Schulte, K., Horres, R., Gonsiska, P.A., Jabaily, R.S., Crayn, D.M., Smith, J.A.C., Winter, K., Brown, G.K., Evans, T.M., Holst, B.K., Luther, H., Till, W., Zizka, G., Berry, P.E., Sytsma, K.J., 2011. Phylogeny, adaptive radiation, and historical biogeography in Bromeliaceae: Insights from an eight-locus plastid phylogeny. Am. J. Bot. 98, 872-895. doi:10.3732/ajb.1000059

Givnish, T.J., Millam, K.C., Berry, P.E., Sytsma, K.J., 2007. Phylogeny, adaptive radiation, and historical biogeography of Bromeliaceae inferred from ndhF sequence data. Aliso J. Syst. Evol. Bot. 23, 3-26. doi:10.5642/aliso.20072301.04 
Givnish, T.J., Millam, K.C., Evans, T.M., Hall, J.C., Pires, J.C., Berry, P.E., Sytsma, K.J., 2004. Ancient vicariance or recent long-distance dispersal? Inferences about phylogeny and South American-African disjunctions in Rapateaceae and Bromeliaceae based on $n d h \mathrm{~F}$ sequence data. Int. J. Plant Sci. 165, 35-54. doi:10.1086/421067

Givnish, T.J., Sytsma, K.J., 2000. Molecular Evolution and Adaptive Radiation. Cambridge University Press.

Goloboff, P.A., 1999. Analyzing large data sets in reasonable times: solutions for composite optima. Cladistics 15, 415-428. doi:10.1111/j.10960031.1999.tb00278.x

Goloboff, P.A., Farris, J.S., Nixon, K.C., 2008. TNT, a free program for phylogenetic analysis. Cladistics 24, 774-786. doi:10.1111/j.1096-0031.2008.00217.x

Guindon, S., Gascuel, O., 2003. A simple, fast, and accurate algorithm to estimate large phylogenies by Maximum Likelihood. Syst. Biol. 52, 696-704. doi:10.1080/10635150390235520

Heller, S., Leme, E.M.C., Schulte, K., Benko-Iseppon, A.M., Zizka, G., 2015. Elucidating phylogenetic relationships in the Aechmea Alliance: AFLP analysis of Portea and the Gravisia complex (Bromeliaceae, Bromelioideae). Syst. Bot. 40, 716-725. doi:DOI 10.1600/036364415X689177

Horres, R., Schulte, K., Weising, K., Zizka, G., 2007. Systematics of Bromelioideae (Bromeliaceae) - evidence from molecular and anatomical studies. Aliso 23, 2743. doi:10.5642/aliso.20072301.05 
Katoh, K., Standley, D.M., 2013. MAFFT multiple sequence alignment software Version 7: improvements in performance and usability. Mol. Biol. Evol. 30, 772-780. doi:10.1093/molbev/mst010

Larget, B.R., Kotha, S.K., Dewey, C.N., Ané, C., 2010. BUCKy: Gene tree/species tree reconciliation with Bayesian concordance analysis. Bioinformatics 26, 29102911. doi:10.1093/bioinformatics/btq539

Leme, E.M.C., Kollmann, L.J., 2011. New species and a new combination of Brazilian Bromeliaceae. Phytotaxa 16136.

Maddison, W.P., Maddison, D.R., 2014. Mesquite: a modular system for evolutionary analysis. URL: http://mesquiteproject.wikispaces.com

Maia, V.H., Mata, C.S. da, Franco, L.O., Cardoso, M.A., Cardoso, S.R.S., Hemerly, A.S., Ferreira, P.C.G., 2012. DNA Barcoding Bromeliaceae: Achievements and Pitfalls. PLoS ONE 7, e29877. doi:10.1371/journal.pone.0029877

Mason-Gamer, R.J., Kellogg, E.A., 1996. Testing for phylogenetic conflict among molecular data sets in the Tribe Triticeae (Gramineae). Syst. Biol. 45, 524-545. doi:10.1093/sysbio/45.4.524

Meade, A., Pagel, M., 2014. BayesTraits v2.0. URL: http://www.evolution.rdg.ac.uk/BayesTraits.html

Mez, C., 1896. Bromeliaceae, in: de Candolle, C. (Ed.), Monographiae Phanerogamarum. Masson, Paris, p. 990.

Miller, M.A., Pfeiffer, W., Schwartz, T., 2011. The CIPRES science gateway: a community resource for phylogenetic analyses. Presented at the Proceedings of the 2011 TeraGrid Conference: Extreme Digital Discovery, ACM, p. 41. 
Paradis, E., Claude, J., Strimmer, K., 2004. APE: Analyses of phylogenetics and evolution in R language. Bioinform. 20, 289-290. doi:10.1093/bioinformatics/btg412

Quezada, I.M., Gianoli, E., 2011. Crassulacean acid metabolism photosynthesis in Bromeliaceae: an evolutionary key innovation. Biol. J. Linn. Soc. 104, 480-486. doi:10.1111/j.1095-8312.2011.01713.x

Rambaut, A., Drummond, A., 2003. Tracer: MCMC trace analysis tool. URL: http://tree.bio.ed.ac.uk/software/tracer/

R Development Core Team, 2015. R: A Language and Environment for Statistical Computing. R Foundation for Statistical Computing, Vienna, Austria.

Revell, L.J., 2012. phytools: an R package for phylogenetic comparative biology (and other things). Methods Ecol. Evol. 3, 217-223. doi:10.1111/j.2041210X.2011.00169.X

Ronquist, F., Teslenko, M., Mark, P. van der, Ayres, D.L., Darling, A., Höhna, S., Larget, B., Liu, L., Suchard, M.A., Huelsenbeck, J.P., 2012. MrBayes 3.2: Efficient bayesian phylogenetic inference and model choice across a large model space. Syst. Biol. 61, 539-542. doi:10.1093/sysbio/sys029

Salinas, N.R., Little, D.P., 2014. 2matrix: A utility for indel coding and phylogenetic matrix concatenation. Appl. Plant Sci. 2, 1300083. doi:10.3732/apps.1300083

Sanderson, M.J., 2002. Estimating absolute rates of molecular evolution and divergence times: A penalized likelihood approach. Mol. Biol. Evol. 19, 101-109. 
Sass, C., Specht, C.D., 2010. Phylogenetic estimation of the core Bromelioids with an emphasis on the genus Aechmea (Bromeliaceae). Mol. Phylogenet. Evol. 55, 559571. doi:10.1016/j.ympev.2010.01.005

Schliep, K.P., 2011. Phangorn: phylogenetic analysis in R. Bioinform. 27, 592-593. doi:10.1093/bioinformatics/btq706

Schulte, K., Barfuss, M.H.J., Zizka, G., 2009. Phylogeny of Bromelioideae (Bromeliaceae) inferred from nuclear and plastid DNA loci reveals the evolution of the tank habit within the subfamily. Mol. Phylogenet. Evol. 51, 327-339. doi:10.1016/j.ympev.2009.02.003

Schulte, K., Horres, R., Zizka, G., 2005. Molecular phylogeny of Bromelioideae and its implications on biogeography and the evolution of CAM in the family (Poales, Bromeliaceae). Senckenberg. Biol. 85, 113.

Schulte, K., Zizka, G., 2008. Multi locus plastid phylogeny of Bromelioideae (Bromeliaceae) and the taxonomic utility of petal appendages and pollen characters. Candollea 63, 209-225.

Shimodaira, H., 2002. An approximately unbiased test of phylogenetic tree selection. Syst. Biol. 51, 492-508. doi:10.1080/10635150290069913

Shimodaira, H., Hasegawa, M., 2001. CONSEL: for assessing the confidence of phylogenetic tree selection. Bioinform. 17, 1246-1247. doi:10.1093/bioinformatics/17.12.1246

Silvestro, D., Zizka, G., Schulte, K., 2014. Disentangling the effects of key innovations on the diversification of Bromelioideae (Bromeliaceae). Evolution 68, 163-175. doi:10.1111/evo.12236 
Siqueira Filho, J.A., Leme, E.M.C., 2006. Fragmentos de Mata Atlântica do Nordeste: biodiversidade, conservação e suas bromélias. Andrea Jakobsson Estúdio.

Smith, L.B., Kress, W.J., 1989. New or restored genera of Bromeliaceae. Phytologia 66, $70-79$.

Smith, L.B., Spencer, M.A., 1992. Reduction of Streptocalyx (Bromeliaceae: Bromelioideae). Phytologia 72, 92-98.

Smith, L.B., Downs, R.J., 1979. Flora Neotropica Monograph: no. 14, part 3. Bromelioideae (Bromeliaceae). N. Y. Bot. Gard. Organ. Flora Neotropica 14932142.

Sousa, L.F.O., Wendt, T., Brown, G.K., Tuthill, D.E., Evans, T.M., 2007. Monophyly and phylogenetic relationships in Lymania (Bromeliaceae : Bromelioideae) based on morphology and plastid DNA sequences. Syst. Bot. 32, 264-270. doi:http://dx.doi.org/10.1600/036364407781179707

Stamatakis, A., 2014. RAxML version 8: a tool for phylogenetic analysis and postanalysis of large phylogenies. Bioinform. 30, 1312-1313. doi:10.1093/bioinformatics/btu033 


\section{$\underline{\text { Tables }}$}

\begin{tabular}{|c|c|c|c|c|c|c|c|c|c|c|c|c|c|}
\hline Taxon & 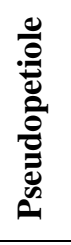 & 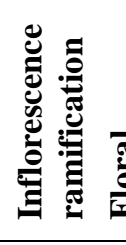 & 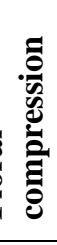 & 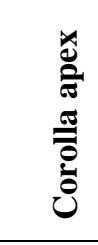 & 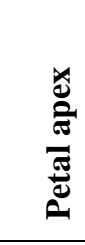 & $\frac{\dot{0}}{\frac{0}{0}}$ & 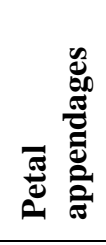 & 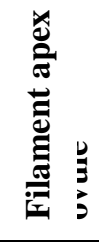 & 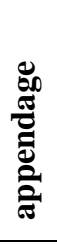 & 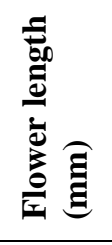 & 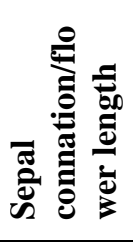 & 突 & 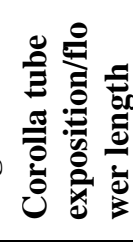 \\
\hline $\begin{array}{l}\text { Acanthostachys } \\
\text { pitcairnioides }\end{array}$ & 1 & 0 & 0 & 0 & 0 & 0 & 0 & 1 & 1 & 40 & 0.05 & 0.025 & 0.375 \\
\hline $\begin{array}{l}\text { Aechmea allenii } \\
1\end{array}$ & 1 & 0 & 0 & 0 & 1 & 0 & 1 & 0 & 0 & 50 & 0.01 & 0.1342 & 0.3 \\
\hline $\begin{array}{l}\text { Aechmea } \\
\text { altocaririensis }\end{array}$ & 0 & 0 & 1 & 0 & 0 & 0 & 0 & 0 & 0 & 15.5 & 0.0484 & 0.129 & 0.3226 \\
\hline $\begin{array}{l}\text { Aechmea } \\
\text { amorimii } 2\end{array}$ & 1 & {$[0,1]$} & 1 & 0 & 0 & 1 & 0 & 0 & 0 & 26.25 & 0.0571 & 0.1238 & 0.2667 \\
\hline $\begin{array}{l}\text { Aechmea } \\
\text { andersoniana } \\
\text { TYPE }\end{array}$ & 1 & 0 & 1 & 0 & 0 & 1 & 0 & 0 & 0 & 15.6 & 0.0962 & 0.1038 & 0.3077 \\
\hline $\begin{array}{l}\text { Aechmea } \\
\text { bicolor } 2\end{array}$ & 1 & 0 & 1 & {$[1,0]$} & 1 & 1 & 1 & 0 & 0 & 17.5 & 0.0714 & 0.0343 & 0.3286 \\
\hline $\begin{array}{l}\text { Aechmea } \\
\text { blumenavii }\end{array}$ & 1 & 0 & 1 & 2 & 1 & 0 & 1 & $?$ & 0 & 16 & 0.125 & 0.1094 & 0.375 \\
\hline $\begin{array}{l}\text { Aechmea } \\
\text { bromeliifolia }\end{array}$ & 1 & 0 & 1 & {$[1,2]$} & 1 & 0 & 1 & 0 & 1 & 14 & 0.0357 & 0.0007 & 0.4286 \\
\hline $\begin{array}{l}\text { Aechmea burle- } \\
\text { marxii }\end{array}$ & 1 & 1 & 1 & 0 & 0 & 1 & 1 & 0 & 0 & 15.75 & 0.0476 & 0.059 & 0.3365 \\
\hline $\begin{array}{l}\text { Aechmea } \\
\text { canaliculata }\end{array}$ & 0 & 0 & 1 & $?$ & $?$ & 1 & 0 & $?$ & 0 & 27 & 0.2593 & 0.0881 & 0.2778 \\
\hline $\begin{array}{l}\text { Aechmea } \\
\text { contracta }\end{array}$ & 0 & {$[0,1]$} & 1 & 2 & 1 & 0 & 1 & 0 & 1 & 26.5 & 0.0075 & 0.0113 & 0.5283 \\
\hline $\begin{array}{l}\text { Aechmea } \\
\text { dactylina }\end{array}$ & 1 & 1 & 0 & 0 & 1 & 0 & 1 & 0 & 1 & 24 & 0 & 0.0417 & 0.2083 \\
\hline $\begin{array}{l}\text { Aechmea } \\
\text { drakeana }\end{array}$ & 1 & 0 & 1 & 0 & 0 & 0 & 1 & 0 & 0 & 45 & 0 & 0.0533 & 0.5911 \\
\hline Aechmea fraseri & 1 & 0 & 1 & 0 & 1 & 0 & 1 & 0 & 0 & 32.5 & 0 & 0.0462 & 0.4923 \\
\hline $\begin{array}{l}\text { Aechmea froesii } \\
1\end{array}$ & 1 & 1 & 1 & 0 & 0 & 1 & 0 & 0 & 0 & 17 & 0.0059 & 0.0741 & 0.1941 \\
\hline $\begin{array}{l}\text { Aechmea froesii } \\
2\end{array}$ & 1 & 1 & 1 & 0 & 0 & 1 & 0 & 0 & 0 & 17 & 0.0059 & 0.0741 & 0.1941 \\
\hline $\begin{array}{l}\text { Aechmea } \\
\text { germinyana } 1\end{array}$ & 1 & 0 & 0 & 0 & 0 & 1 & 1 & 1 & 0 & 23 & 0 & 0.0109 & 0.2826 \\
\hline $\begin{array}{l}\text { Aechmea } \\
\text { incompta TYPE }\end{array}$ & 1 & 1 & 1 & 0 & 0 & 1 & 0 & 0 & 0 & 14.6 & 0.0137 & 0.1267 & 0.2808 \\
\hline $\begin{array}{l}\text { Aechmea } \\
\text { involucrata }\end{array}$ & 1 & 0 & 1 & 0 & 1 & 0 & 1 & 0 & 0 & 42.2 & 0.0355 & 0.0758 & 0.4443 \\
\hline $\begin{array}{l}\text { Aechmea } \\
\text { ituberaensis }\end{array}$ & 1 & 0 & 1 & 0 & 0 & 1 & 0 & 0 & 0 & 18.4 & 0.1087 & 0.0739 & 0.2245 \\
\hline
\end{tabular}




\begin{tabular}{|c|c|c|c|c|c|c|c|c|c|c|c|c|c|}
\hline $\begin{array}{l}\text { Aechmea } \\
\text { laevigata }\end{array}$ & 1 & 1 & 1 & 0 & 1 & 1 & 1 & 0 & 0 & 18 & 0.1111 & 0.0694 & 0.2556 \\
\hline Aechmea limae & 1 & 0 & 1 & 0 & 1 & 1 & 0 & 0 & 0 & 12.5 & 0.14 & 0.072 & 0.5104 \\
\hline $\begin{array}{l}\text { Aechmea } \\
\text { lingulata }\end{array}$ & & & & & & & & & & & & & \\
\hline ANTIGUA & 1 & 1 & 1 & 0 & 0 & 1 & 0 & 0 & 0 & 14.5 & 0.0517 & 0.1724 & 0.3448 \\
\hline $\begin{array}{l}\text { Aechmea } \\
\text { lingulatoides } 1\end{array}$ & 1 & 1 & 1 & 0 & 0 & 1 & 0 & 0 & 0 & 13.13 & 0.0228 & 0.1714 & 0.3732 \\
\hline $\begin{array}{l}\text { Aechmea } \\
\text { lingulatoides }\end{array}$ & & & & & & & & & & & & & \\
\hline TYPE & 1 & 1 & 1 & 0 & 0 & 1 & 0 & 0 & 0 & 13.13 & 0.0228 & 0.1714 & 0.3732 \\
\hline $\begin{array}{l}\text { Aechmea } \\
\text { linharesiorum }\end{array}$ & 1 & 1 & 1 & 0 & 0 & 1 & 0 & 0 & 0 & 9.41 & 0.0425 & 0.085 & 0.3039 \\
\hline $\begin{array}{l}\text { Aechmea } \\
\text { maranguapensis }\end{array}$ & 1 & 1 & 1 & 0 & 0 & 0 & 0 & 0 & 0 & 16.6 & 0.0904 & 0.106 & 0.3241 \\
\hline $\begin{array}{l}\text { Aechmea maria } \\
\text { regiane }\end{array}$ & 1 & 0 & 0 & 2 & 1 & 0 & 1 & 0 & 1 & 20 & 0 & 0.15 & 0.25 \\
\hline $\begin{array}{l}\text { Aechmea } \\
\text { nudicaulis }\end{array}$ & & & & & & & & & & & & & \\
\hline COSTA RICA & 1 & 0 & 1 & 0 & 1 & 0 & 1 & 0 & 0 & 16.5 & 0.0303 & 0.0485 & 0.3636 \\
\hline $\begin{array}{l}\text { Aechmea } \\
\text { patentissima } 1\end{array}$ & 1 & 1 & 1 & 0 & 0 & 0 & 0 & 0 & 0 & 13.9 & 0.0669 & 0.123 & 0.2662 \\
\hline $\begin{array}{l}\text { Aechmea } \\
\text { patentissima } 2\end{array}$ & 1 & 1 & 1 & 0 & 0 & 0 & 0 & 0 & 0 & 13.9 & 0.0669 & 0.123 & 0.2662 \\
\hline $\begin{array}{l}\text { Aechmea } \\
\text { subintegerrima }\end{array}$ & & & & & & & & & & & & & \\
\hline $\begin{array}{l}\text { I } \\
\text { Aechmea } \\
\text { sulbahianensis }\end{array}$ & 1 & 0 & 1 & 0 & 1 & 0 & 0 & 1 & 0 & 18.75 & 0.0624 & 0.0347 & 0.24 \\
\hline 1 & 1 & 1 & 1 & 0 & 0 & 1 & 0 & 0 & 0 & 10.5 & 0.0476 & 0.0905 & 0.2381 \\
\hline $\begin{array}{l}\text { Aechmea } \\
\text { sulbahianensis } \\
\text { TYPE }\end{array}$ & 1 & 1 & 1 & 0 & 0 & 1 & 0 & 0 & 0 & 10.5 & 0.0476 & 0.0905 & 0.2381 \\
\hline $\begin{array}{l}\text { Aechmea } \\
\text { tentaculifera }\end{array}$ & 1 & 1 & 1 & 0 & 0 & 1 & 1 & 0 & 0 & 18.5 & 0.0405 & 0.0865 & 0.3784 \\
\hline $\begin{array}{l}\text { Aechmea } \\
\text { tonduzii } \\
\text { ECUADOR }\end{array}$ & 1 & 0 & 1 & 0 & 1 & $\begin{array}{l}{[1,} \\
0]\end{array}$ & 1 & 1 & 0 & 19.13 & 0.1004 & 0.0423 & 0.3074 \\
\hline $\begin{array}{l}\text { Aechmea } \\
\text { turbinocalyx } 1\end{array}$ & 1 & {$[0,1]$} & 1 & 0 & 0 & 1 & 0 & 0 & 0 & 17.6 & 0.0142 & 0.0994 & 0.2841 \\
\hline $\begin{array}{l}\text { Aechmea } \\
\text { veitchii }\end{array}$ & 1 & 0 & 0 & 0 & {$[1,0]$} & 1 & 1 & 1 & 0 & 23 & 0 & 0.0087 & 0.2174 \\
\hline $\begin{array}{l}\text { Aechmea } \\
\text { viridostigma } \\
\text { TYPE }\end{array}$ & 1 & 1 & 1 & 0 & 0 & 1 & 1 & 0 & 0 & 18.33 & 0.0546 & 0.1091 & 0.4364 \\
\hline $\begin{array}{l}\text { Aechmea } \\
\text { weberbaueri } \\
\text { Ananas }\end{array}$ & 1 & 0 & 1 & 0 & 1 & 0 & 1 & 0 & 0 & 43.22 & 0.0116 & 0.2152 & 0.4496 \\
\hline comosus & 1 & 0 & 0 & 1 & 1 & 0 & 1 & 0 & 0 & 20 & 0 & 0.01 & 0.4 \\
\hline $\begin{array}{l}\text { Disteganthus } \\
\text { morii }\end{array}$ & 0 & 0 & 0 & 0 & 0 & 0 & 0 & 0 & 0 & 63 & 0.1429 & 0.0032 & 0.2381 \\
\hline
\end{tabular}


Hohenbergia abbreviata

Hohenbergia andina 1

Hohenbergia antillana 2

Hohenbergia caymanensis

Hohenbergia correia-araujoi

Hohenbergia

distans 1

Hohenbergia distans 2

Hohenbergia eriostachya

Hohenbergia fawcettii

Hohenbergia inermis

Hohenbergia jamaicana

Hohenbergia laesslei

Hohenbergia mesoamericana

Hohenbergia negrilensis

Hohenbergia penduliflora CUBA

Hohenbergia polycephala

Hohenbergia portoricensis 2

Hohenbergia

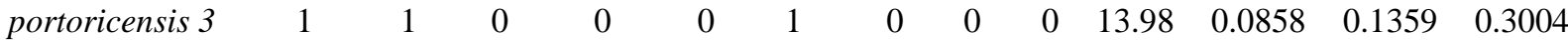
Hohenbergia $s p$ nov

Hohenbergia spinulosa 1

Hohenbergia urbaniana

Lymania

spiculata

Ronnbergia columbiana 2

Ronnbergia deleonii 1

Ronnbergia deleonii 2

\begin{tabular}{|c|c|c|c|c|c|c|c|c|c|c|c|c|c|}
\hline 1 & 1 & 0 & 0 & & & 1 & 1 & 0 & 0 & 11.83 & 0.0634 & 0.0845 & 0.366 \\
\hline 1 & 1 & 0 & 0 & & & 1 & 1 & 0 & 1 & 29 & 0.0103 & 0.069 & 0.1724 \\
\hline 1 & 1 & 0 & 0 & & & 1 & 0 & 0 & 0 & 18.67 & 0.0536 & 0.1018 & 0.2678 \\
\hline 1 & 1 & 0 & 0 & & & 0 & 1 & 0 & 0 & 12.33 & 0.0203 & 0.2822 & 0.365 \\
\hline 1 & 1 & 0 & 0 & & & 0 & 1 & 0 & 1 & 16 & 0 & 0.0625 & 0.3125 \\
\hline 1 & 1 & 0 & 0 & & & 1 & 1 & 0 & 0 & 14.93 & 0.0603 & 0.069 & 0.4106 \\
\hline 1 & 1 & 0 & 0 & & & 1 & 1 & 0 & 0 & 14.93 & 0.0603 & 0.069 & 0.4106 \\
\hline 1 & 1 & 0 & 0 & & & 1 & 0 & 0 & 0 & 9 & 0.0667 & 0.0944 & 0.3633 \\
\hline 1 & 1 & 0 & 0 & & & 1 & 1 & 0 & 0 & 15.38 & 0.0455 & 0.039 & 0.4129 \\
\hline 1 & 1 & 0 & 0 & & & 1 & 1 & 0 & 0 & 17.5 & 0.08 & 0.0417 & 0.2286 \\
\hline 1 & 1 & 0 & & ? & & & & 0 & 0 & ? & $?$ & $?$ & $?$ \\
\hline 1 & 1 & 0 & 0 & & & 1 & 1 & 0 & 0 & 11 & 0.0455 & 0.0864 & 0.3182 \\
\hline 1 & 1 & 0 & 0 & & & 0 & 1 & 0 & 0 & 15 & 0.0333 & 0.1867 & 0.3333 \\
\hline 1 & 1 & 0 & 0 & & & 1 & 1 & 0 & 0 & 14.25 & 0 & 0.0933 & 0.3684 \\
\hline 1 & 1 & 0 & 0 & & & 1 & 1 & 0 & 0 & 16.25 & 0.0615 & 0.0818 & 0.3895 \\
\hline 1 & 1 & 0 & 0 & & & 1 & 0 & 0 & 0 & 9 & 0.0556 & 0.0778 & 0.3333 \\
\hline 1 & 1 & 0 & 0 & & & 1 & 0 & 0 & 0 & 13.98 & 0.0858 & 0.1359 & 0.3004 \\
\hline 1 & 1 & 0 & 0 & & & 1 & 0 & 0 & 0 & 13.98 & 0.0858 & 0.1359 & 0.3004 \\
\hline 1 & 1 & 0 & 0 & & & 1 & 1 & 0 & 0 & 14.25 & 0.1404 & 0.1242 & 0.3684 \\
\hline 1 & 1 & 0 & 0 & & & $\begin{array}{l}\text { 1, } \\
\text { ] }\end{array}$ & 1 & 0 & 0 & 13 & 0.0577 & 0.21 & 0.4231 \\
\hline 1 & 1 & 0 & 0 & & & 1 & 1 & 0 & 0 & 24.5 & 0.0612 & 0.0796 & 0.2176 \\
\hline 1 & 1 & 1 & 0 & & & 1 & 0 & 0 & 1 & 12 & 0.125 & 0.0008 & 0.4167 \\
\hline 0 & 0 & 1 & 0 & & & 1 & 0 & 0 & 0 & 38 & 0.0526 & 0.0408 & 0.5439 \\
\hline 0 & 0 & 1 & 0 & & & 1 & 0 & 0 & 0 & 38 & 0.1218 & 0.1361 & 0.3487 \\
\hline 0 & 0 & 1 & 0 & & & 0 & 0 & 1 & 0 & 38 & 0.1218 & 0.1361 & 0.3487 \\
\hline
\end{tabular}




\begin{tabular}{|c|c|c|c|c|c|c|c|c|c|c|c|c|c|}
\hline $\begin{array}{l}\text { Ronnbergia } \\
\text { explodens }\end{array}$ & 0 & 0 & 1 & $?$ & $?$ & 1 & $?$ & $?$ & $?$ & 30.29 & 0.0825 & 0.0142 & 0.5612 \\
\hline Ronnbergia & & & & & & & & & & & & & \\
\hline killipiana & 0 & 0 & 1 & 0 & 1 & 0 & 0 & 1 & 0 & 28.17 & 0.1154 & 0.0004 & 0.5538 \\
\hline $\begin{array}{l}\text { Ronnbergia } \\
\text { maidifolia } 1\end{array}$ & 0 & 0 & 1 & 0 & 1 & 0 & 0 & 1 & 0 & 27.67 & 0.1265 & 0.0163 & 0.4095 \\
\hline $\begin{array}{l}\text { Ronnbergia } \\
\text { maidifolia } 3\end{array}$ & 0 & 0 & 1 & 0 & 1 & 0 & 0 & 1 & 0 & 27.67 & 0.1265 & 0.0163 & 0.4095 \\
\hline $\begin{array}{l}\text { Ronnbergia } \\
\text { morreniana } 1\end{array}$ & 0 & 0 & 1 & 0 & 1 & 0 & 0 & 1 & 0 & 24.75 & 0.1038 & 0.0202 & 0.4747 \\
\hline $\begin{array}{l}\text { Ronnbergia } \\
\text { morreniana } 2\end{array}$ & 0 & 0 & 1 & 0 & 1 & 0 & 0 & 1 & 0 & 24.75 & 0.1038 & 0.0202 & 0.4747 \\
\hline $\begin{array}{l}\text { Ronnbergia } \\
\text { neoregelioides }\end{array}$ & 1 & 0 & 1 & 0 & 0 & 0 & 0 & 0 & 0 & 37.5 & 0.1021 & 0.0533 & 0.2133 \\
\hline $\begin{array}{l}\text { Ronnbergia } \\
\text { nidularioides }\end{array}$ & 1 & 0 & 0 & 0 & {$[1,0]$} & 0 & 0 & 0 & 0 & 46.67 & 0.0107 & 0.1052 & 0.375 \\
\hline $\begin{array}{l}\text { Ronnbergia } \\
\text { petersii }\end{array}$ & 1 & 0 & 1 & 0 & 1 & $\begin{array}{l}{[1,} \\
0]\end{array}$ & 0 & 0 & 0 & 41.6 & 0.0721 & 0.2685 & 0.3606 \\
\hline $\begin{array}{l}\text { Ronnbergia } \\
\text { silvana }\end{array}$ & 1 & 0 & 1 & 0 & 0 & 0 & 0 & 0 & 0 & 32.25 & 0.1085 & 0.1085 & 0.2326 \\
\hline $\begin{array}{l}\text { Ronnbergia sp } \\
\text { nov }\end{array}$ & 1 & {$[0,1]$} & 1 & 0 & 0 & 0 & 0 & 0 & 0 & $?$ & $?$ & $?$ & $?$ \\
\hline $\begin{array}{l}\text { Ursulaea } \\
\text { tuitensis }\end{array}$ & 1 & 0 & 1 & 0 & 0 & 0 & 1 & 0 & $?$ & 57 & 0.0175 & 0.0526 & 0.2982 \\
\hline
\end{tabular}

Table 1. Morphological data matrix. Scores in brackets represent polymorphic character states. Question mark (?) represents unknown data.

\begin{tabular}{lrrll}
\hline $\begin{array}{l}\text { DNA } \\
\text { region }\end{array}$ & Terminals & $\begin{array}{l}\text { Alignment } \\
\text { length (bp) }\end{array}$ & $\begin{array}{l}\text { Variable } \\
\text { characters } \\
\text { (percent) }\end{array}$ & $\begin{array}{l}\text { Parsimony- } \\
\text { informative } \\
\text { characters }\end{array}$ \\
\hline ETS & 154 & 542 & $295(54.4 \%)$ & $216(39.9 \%)$ \\
g3pdh & 144 & 1211 & $510(42.1 \%)$ & $288(23.8 \%)$ \\
rpb2 & 155 & 360 & $121(33.6 \%)$ & $57(15.8 \%)$ \\
matK-trnK & 163 & 1707 & $217(12.7 \%)$ & $127(7.4 \%)$ \\
trnK-rps16 & 160 & 941 & $152(16.2 \%)$ & $76(8.1 \%)$ \\
trnL-F & 160 & 1039 & $156(15 \%)$ & $75(7.2 \%)$ \\
cpDNA & 168 & 3687 & $525(14.2 \%)$ & $278(7.5 \%)$ \\
nrDNA & 167 & 2113 & $926(43.8 \%)$ & $561(26.5 \%)$ \\
Combined & 168 & 5800 & $1451(25 \%)$ & $839(14.5 \%)$ \\
\hline
\end{tabular}

Table 2. Summary statistics for all alignments. (bp: base pairs). 


\section{Figure Captions}

Figure 1. Representative species of the three species complexes and allied species of Aechmea of the Ronnbergia Alliance sampled in this study. A. Ronnbergia maidifolia. B. Ronnbergia hathewayi. C. Aechmea involucrata. D. Aechmea germinyana. E. Aechmea burle-marxii. F. Hohenbergia urbaniana. G. Aechmea andersoniana. (A. J. Betancur. BC, E, G. Courtesy of the Marie Selby Botanical Gardens research center. D, F. J. Aguirre-Santoro).

Figure 2. 50\% Majority rule consensus tree of the Bayesian Inference analysis using the cpDNA and nrDNA datasets independently. Left: cpDNA topology. Right: nrDNA topology. Names in red correspond to species of the Ronnbergia Alliance. Numbers on the nodes correspond to posterior probabilities and the bar next to the trees represents the number of nucleotide substitutions per site. Symbols in front of the terminals represent the subgenera of Aechmea: Aechmea subg. Aechmea (black circle); Aechmea subg. Chevaliera (white square); Aechmea subg. Macrochordion (white rhombus); Aechmea subg. Ortigiesia (white triangle); Aechmea subg. Platyaechmea (black square); Aechmea subg. Podaechmea (black triangle); Aechmea subg. Pothuava (white circle).

Figure 3. 50\% Majority rule consensus tree of the Bayesian Inference analysis using the combined dataset. Numbers on the nodes correspond to posterior probabilities, followed by a representation of node confidence of the MP/ML analyses; the start symbol (*) represents bootstrap values $\geq 60 \%$; hyphen (-) represents bootstrap values below $60 \%$. Nodes are labeled according to clade names: Core Bromelioideae (C.B.), Pacific Clade (P.C.), Atlantic Clade (A. C.), Caribbean Clade (C.C.), Clade A (A), Clade B (B), Clade 
C (C), and Clade D (D). Symbols in front of the terminals represent the subgenera of Aechmea: Aechmea subg. Aechmea (black circle); Aechmea subg. Chevaliera (white square); Aechmea subg. Macrochordion (white rhombus); Aechmea subg. Ortigiesia (white triangle); Aechmea subg. Platyaechmea (black square); Aechmea subg. Podaechmea (black triangle); Aechmea subg. Pothuava (white circle). Bottom left: geographic distribution of the species in the Ronnbergia Alliance; colors correspond to the clades where the species belong, except for the widespread Aechmea lingulata (red). Data source: Global Biodiversity Information Facility (GBIF) and speciesLink-CRIA. Figure 4. Bayesian ancestral character state reconstruction (BI-ASR) of corolla apex and chalazal ovule appendages. Nodes are labeled according to clade names: Core Bromelioideae (C.B.), Pacific Clade (P.C.), Atlantic Clade (A. C.), Caribbean Clade (C.C.), Clade A (A), Clade B (B), Clade C (C), and Clade D (D). Start symbol (*) shows the results of alternative character reconstructions obtained with ML-ASR for a given node.

Figure 5. Bayesian ancestral character state reconstruction (BI-ASR) of petal apex and petal color. Nodes are labeled according to clade names: Core Bromelioideae (C.B.), Pacific Clade (P.C.), Atlantic Clade (A. C.), Caribbean Clade (C.C.), Clade A (A), Clade B (B), Clade C (C), and Clade D (D).

Figure 6. Bayesian ancestral character state reconstruction (BI-ASR) of inflorescence ramification and petal appendages. Nodes are labeled according to clade names: Core Bromelioideae (C.B.), Pacific Clade (P.C.), Atlantic Clade (A. C.), Caribbean Clade (C.C.), Clade A (A), Clade B (B), Clade C (C), and Clade D (D). Start symbol (*) shows 
the results of alternative character reconstructions obtained with ML-ASR for a given node.

Figure 7. Bayesian ancestral character state reconstruction (BI-ASR) of pseudopetiole, dorsoventral floral compression, and filament apex. Nodes are labeled according to clade names: Core Bromelioideae (C.B.), Pacific Clade (P.C.), Atlantic Clade (A. C.), Caribbean Clade (C.C.), Clade A (A), Clade B (B), Clade C (C), and Clade D (D). Start symbol (*) shows the results of alternative character reconstructions obtained with MLASR for a given node.

Figure 8. Maximum likelihood ancestral character state reconstruction of flower length and corolla tube exposition to flower length ratio. Nodes are labeled according to clade names: Core Bromelioideae (C.B.), Pacific Clade (P.C.), Atlantic Clade (A. C.), Caribbean Clade (C.C.), Clade A (A), Clade B (B), Clade C (C), and Clade D (D). Figure 9. Maximum likelihood ancestral character state reconstruction of sepal connation to flower length ratio and sepal mucro length to flower length ratio. Nodes are labeled according to clade names: Core Bromelioideae (C.B.), Pacific Clade (P.C.), Atlantic Clade (A. C.), Caribbean Clade (C.C.), Clade A (A), Clade B (B), Clade C (C), and Clade $\mathrm{D}(\mathrm{D})$. 

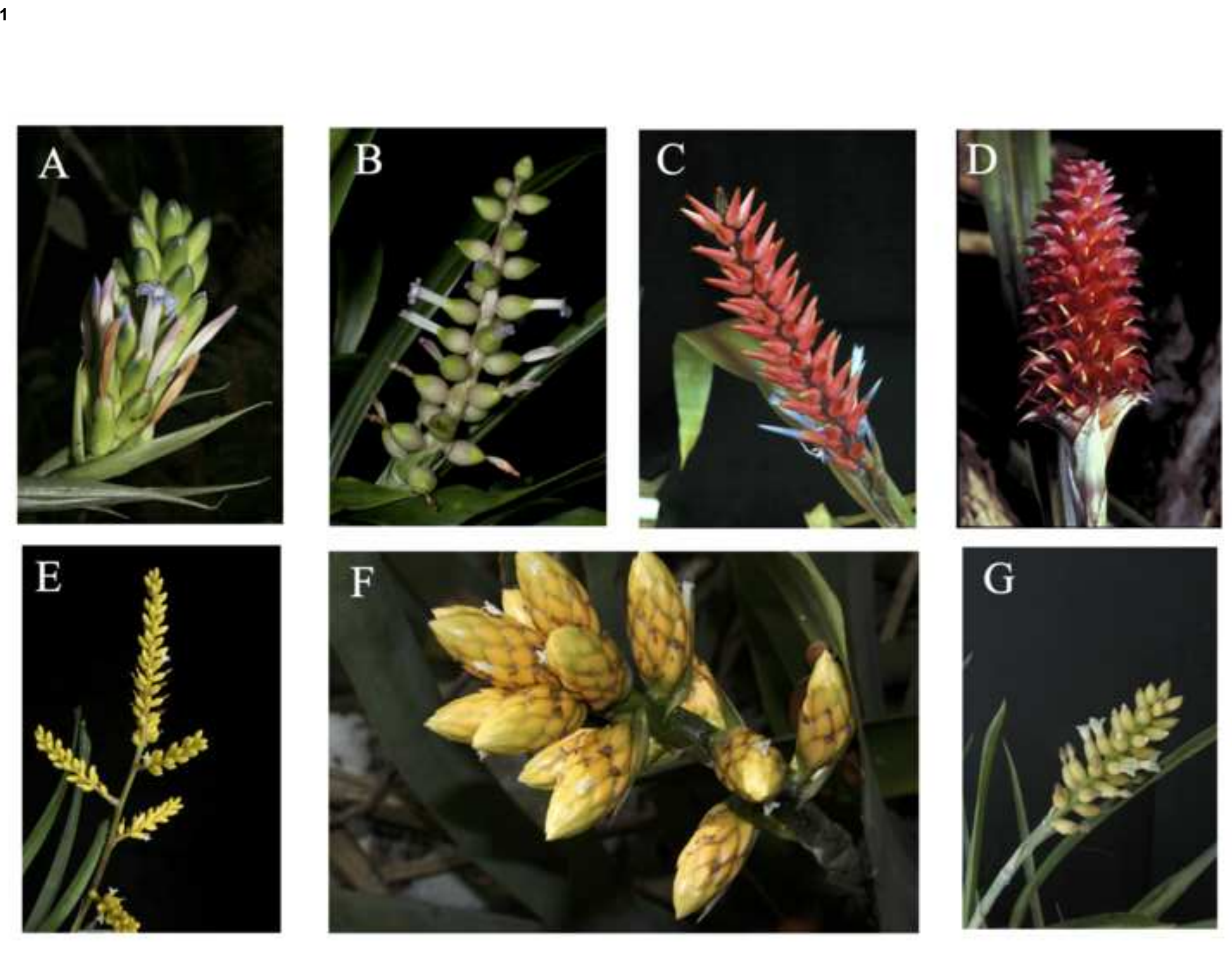


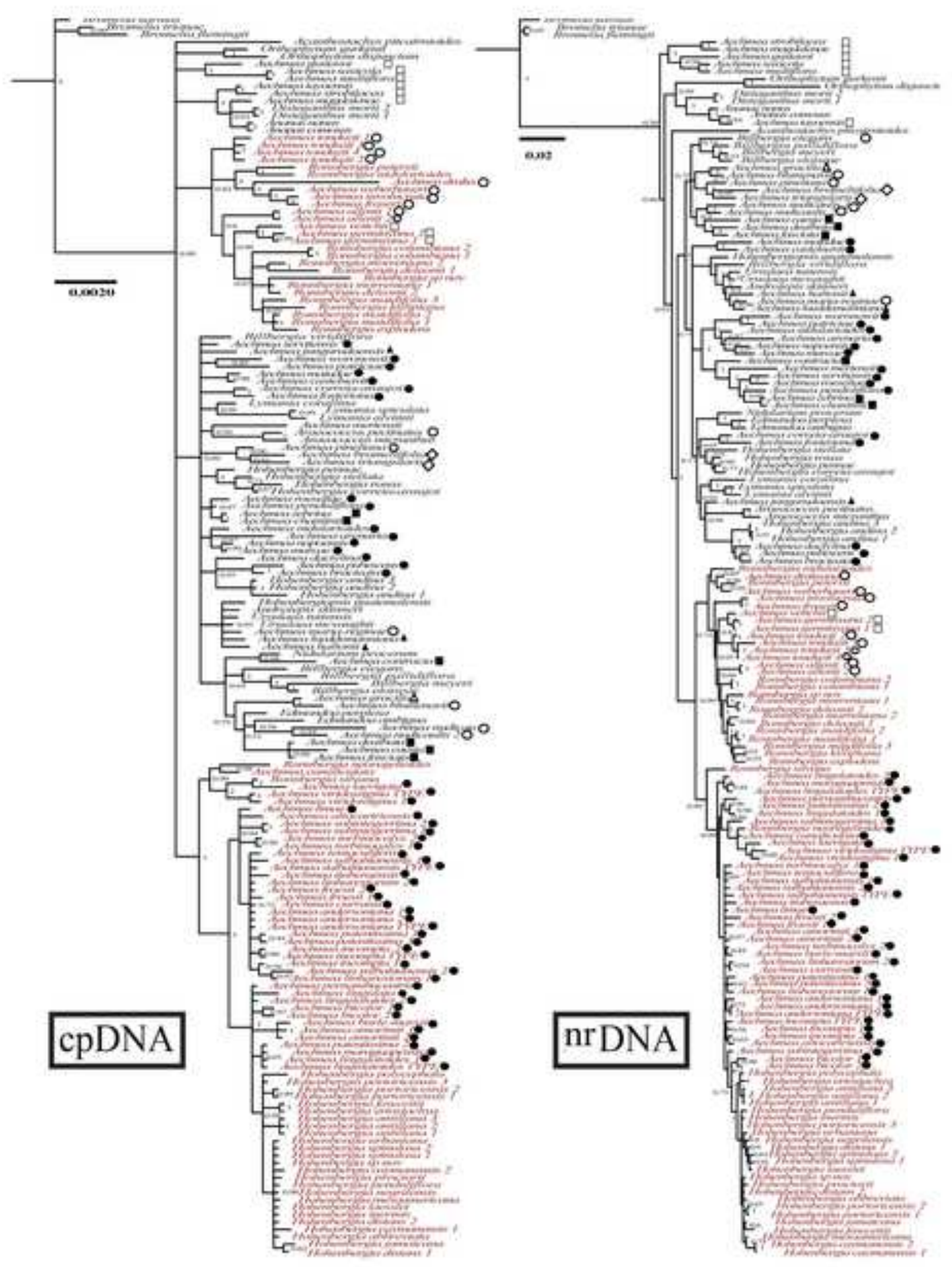

Figure 2 


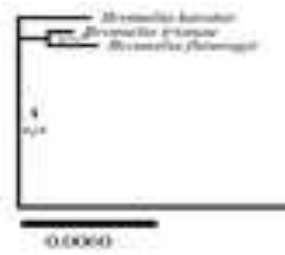

- Pacific clade

- Brazilian specics of the Atluntic clade

- Acchmea lingalata

- Caribbean elade

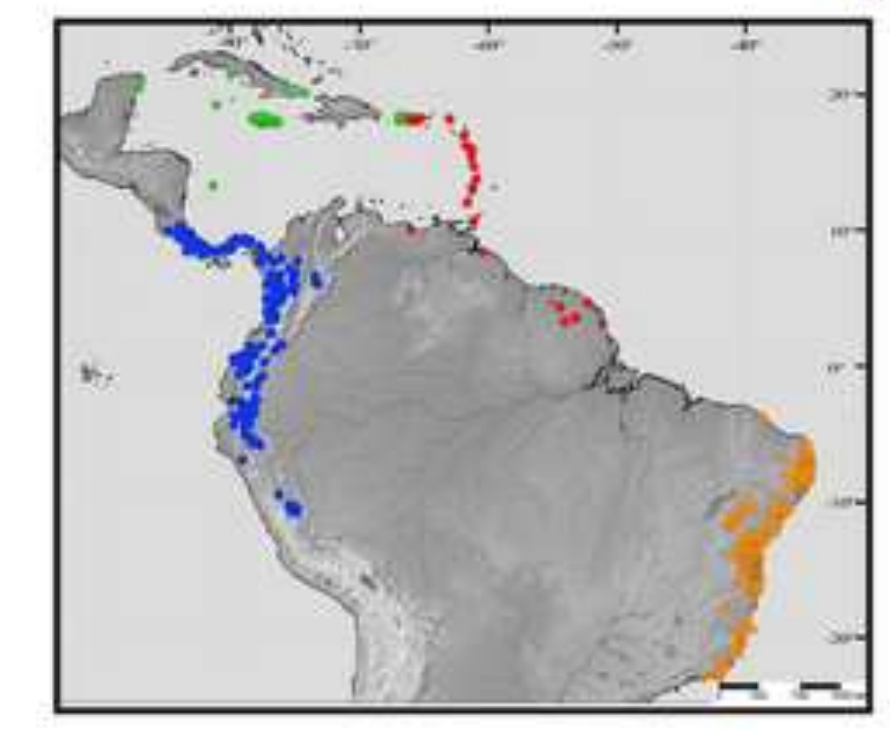

R.A.

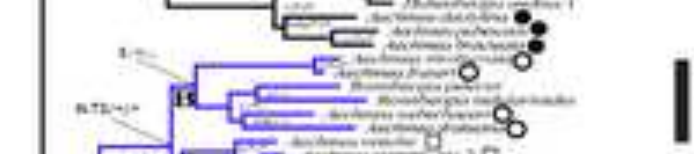

Clacle $B$

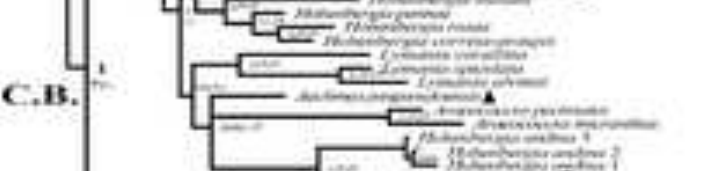

Cincle $B$

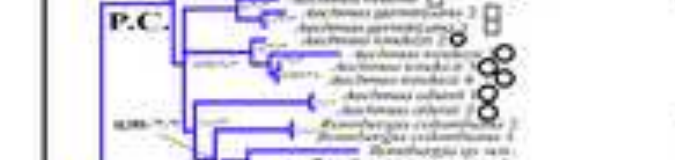

Figure
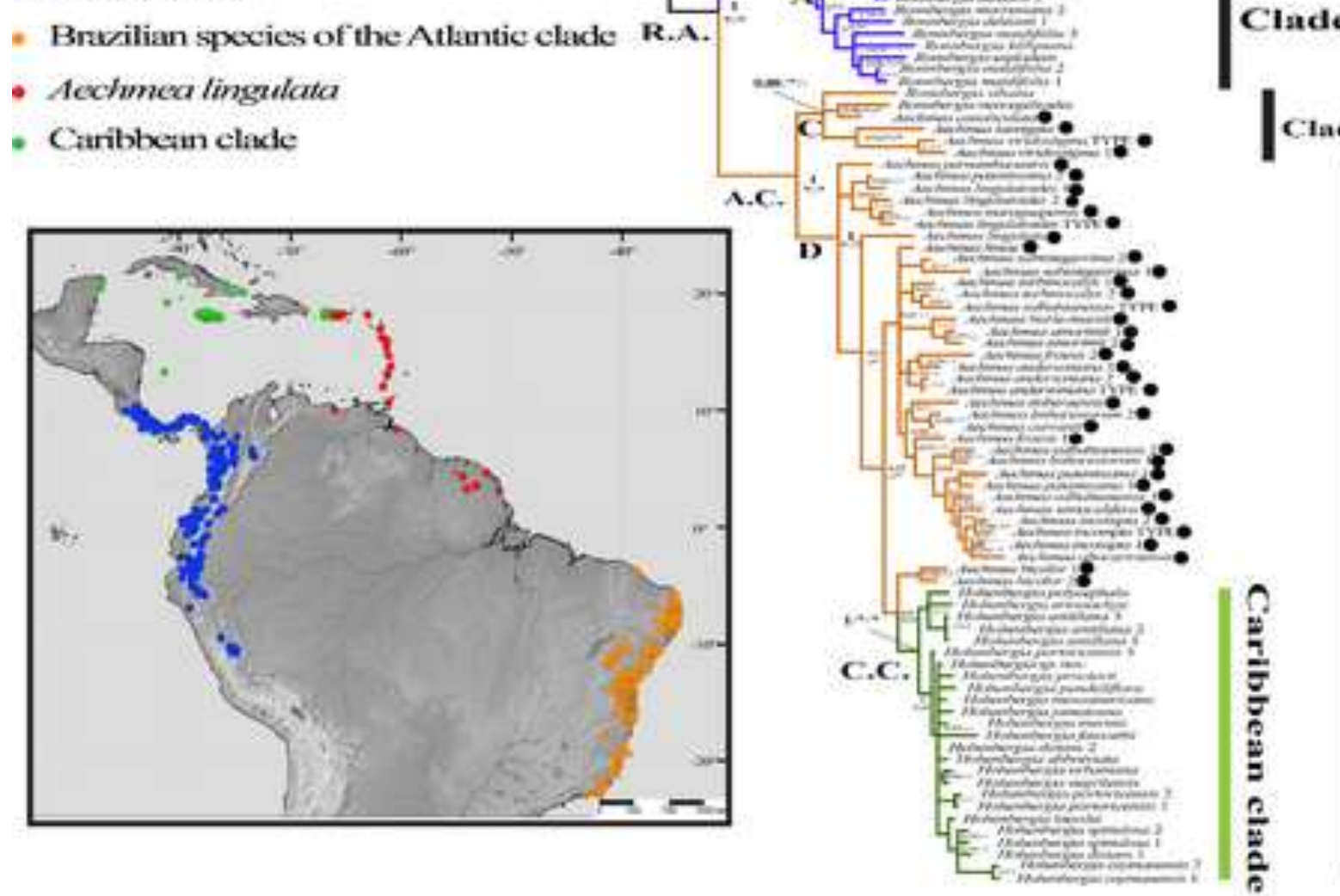


\section{Corolla apex}
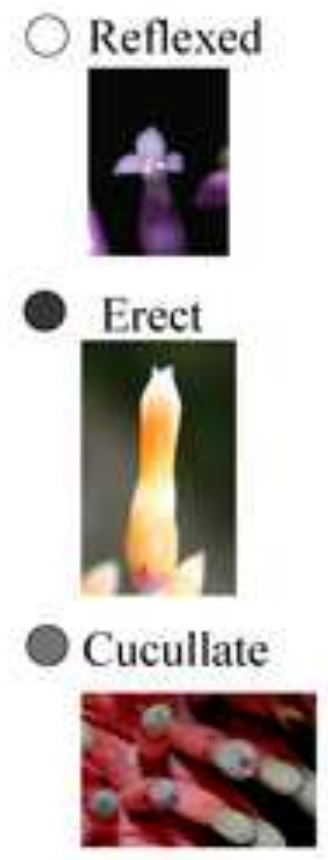

$\mathcal{F}_{\text {C.B. }}$

A.C.
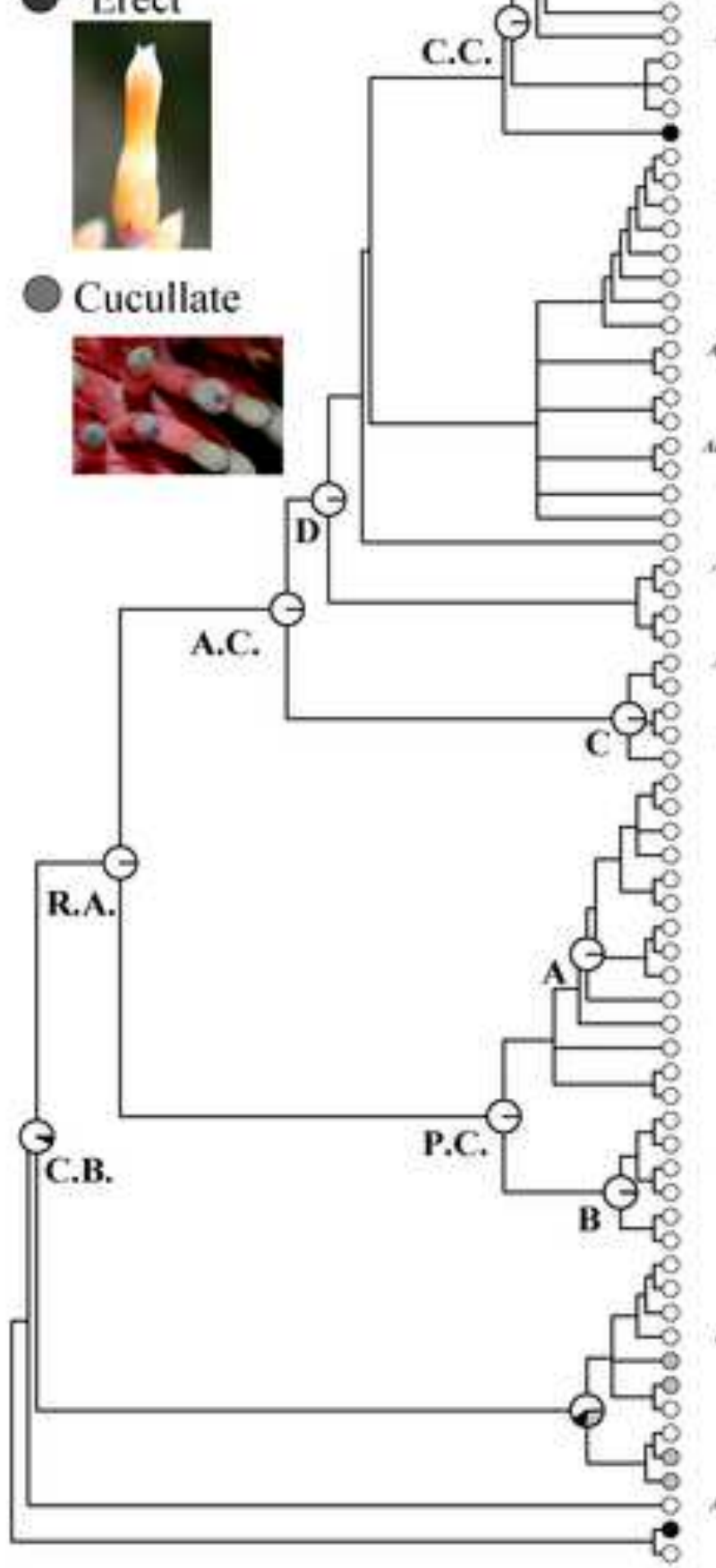

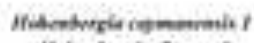

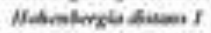

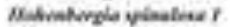

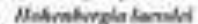

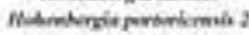
Matimlinde acomillati Matrehinglembalas: Mintretorgia abtorniats Mebrokrsil ditem?

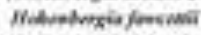
Mrituabrgela immodt

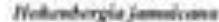

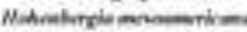

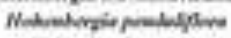

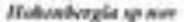

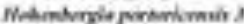
Mabubrgit molion? Nibinkmie wiveatye

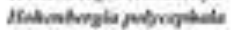

Anheres thester?

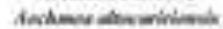

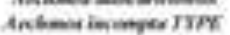

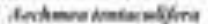

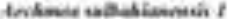

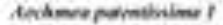

Anteres listurniereat Anikmeremena

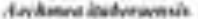
Andews andromian Irr Anchevefhardil 2

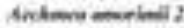

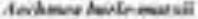

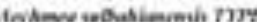

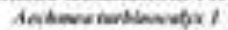

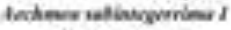
teraterther daber llecedes

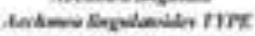

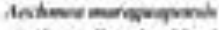

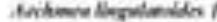
fNAme pernelvime?

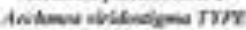
Conders levicas

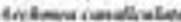

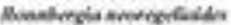
oneatogia bilines

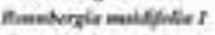
Alemborale coxtulim:

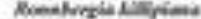

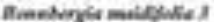

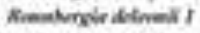

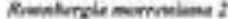

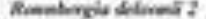

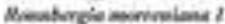
Nematoriolor ver

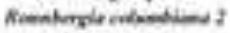

Arrimese ellinal I

indoratumber?

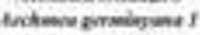
AnAmewavall teskews dudrew

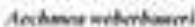

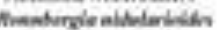
Anemberole fivirie

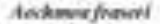

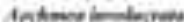

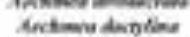

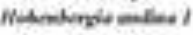
traneis ipciales.

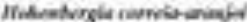
Aabove inemows twitare marbengite

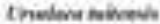
Awbore edrath ! Covbere Abimmara

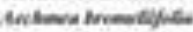

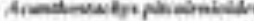

A tomer remes:

Nurqueter Dal?

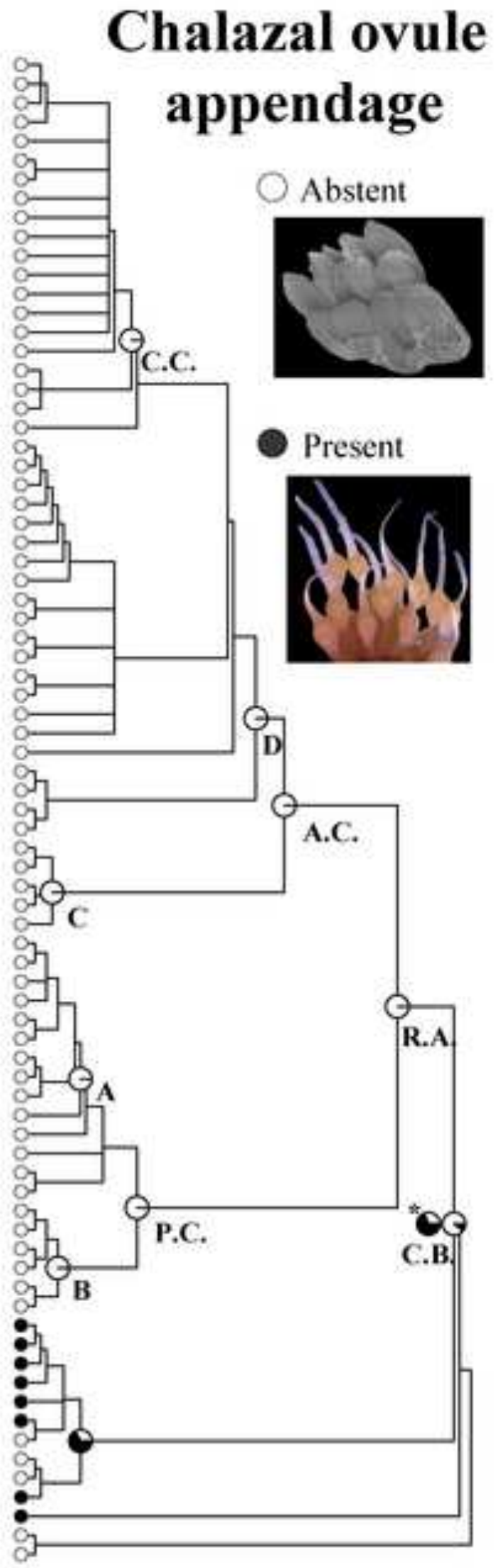




\section{Petal apex}

Acuminate to acute

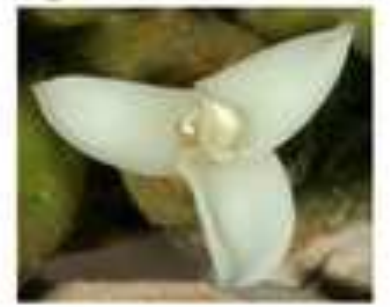

C.C.

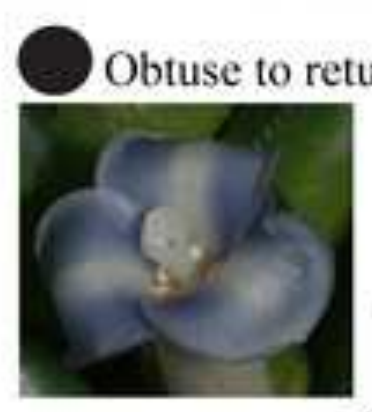

\section{8}

$\mathbb{C}^{\infty}$

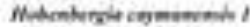

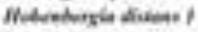

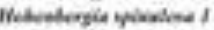
Mebindergeta fensin

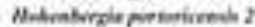

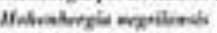

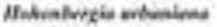

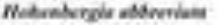

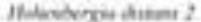

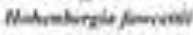

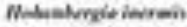
Molnotrople jenabies

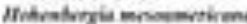

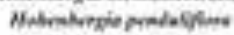
Matimlergit on -

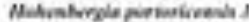

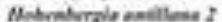

Melvedorita mintos he

Mulimargis polverplale

Conimie Bhelio?

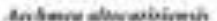

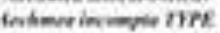

Anthen mavablepor

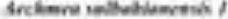

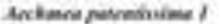

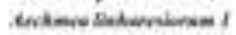
entane pencis

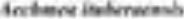

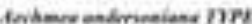

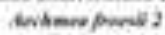

Aevimus enerient?

Andimne Merimmarsi

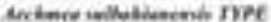

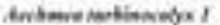

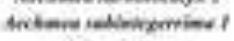

Anctarevilinat

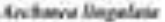

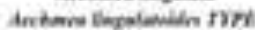

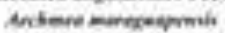

An bevere Eesoluvidis I

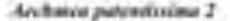

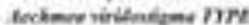

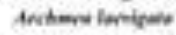

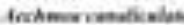

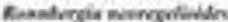

Kenaberia nithes

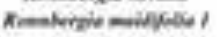

Amelveria eychelvar

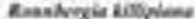

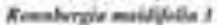

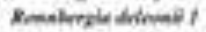

Cenabroxir memeliats

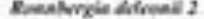

Rinnturgite mempisas If

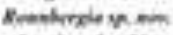

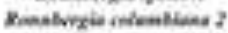

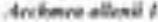

interes onsos?

incione nermigyese t

Ancines mike.

Anbames brainem

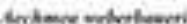

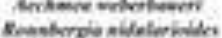

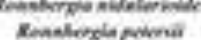

Aectenefreser

inderex invelecrest

inderver desolies

Nabrelonde endias if

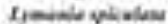

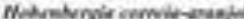

Mvidere ruswats

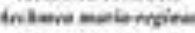

Chalves iminesis.

ferdmer medicediof

Antervi Nomente

temberes Anventible

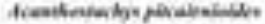

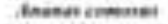

Alvrenthas mine if
Petal color

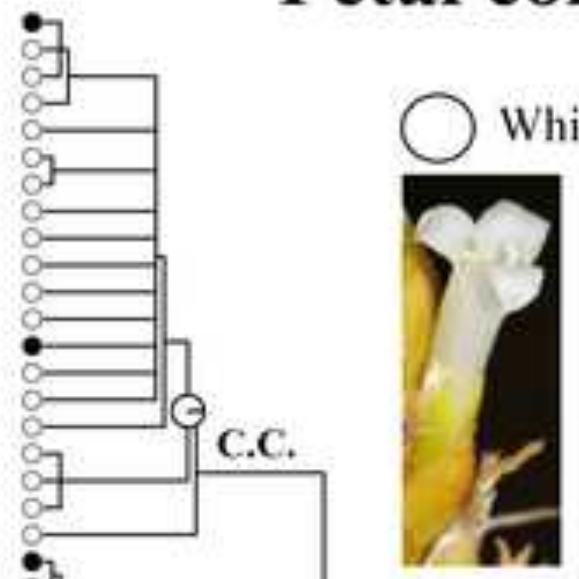

Pigmented

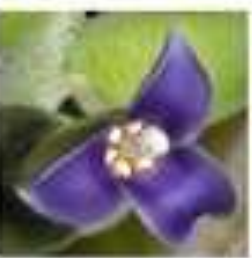

ID

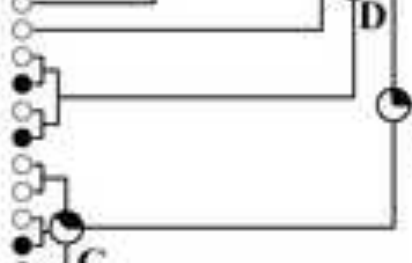

A.C.

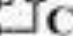

:-

9

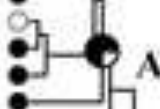

R.A.

P.C.

C.B.

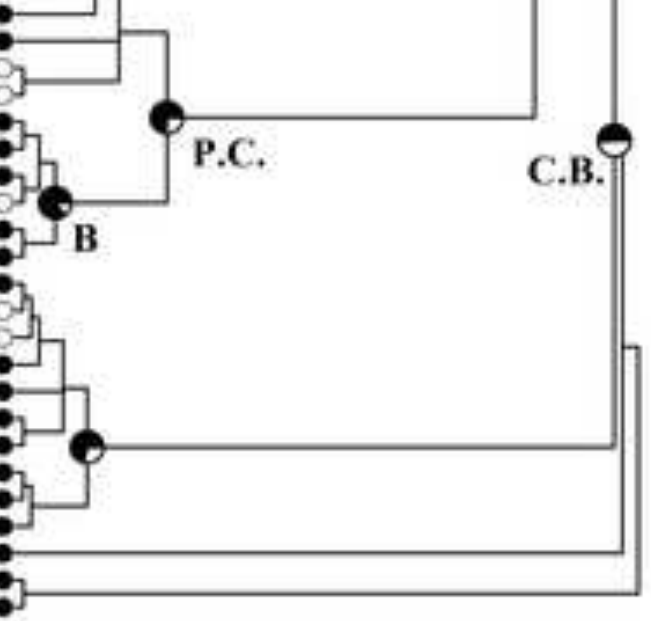




\section{Inflorescence}

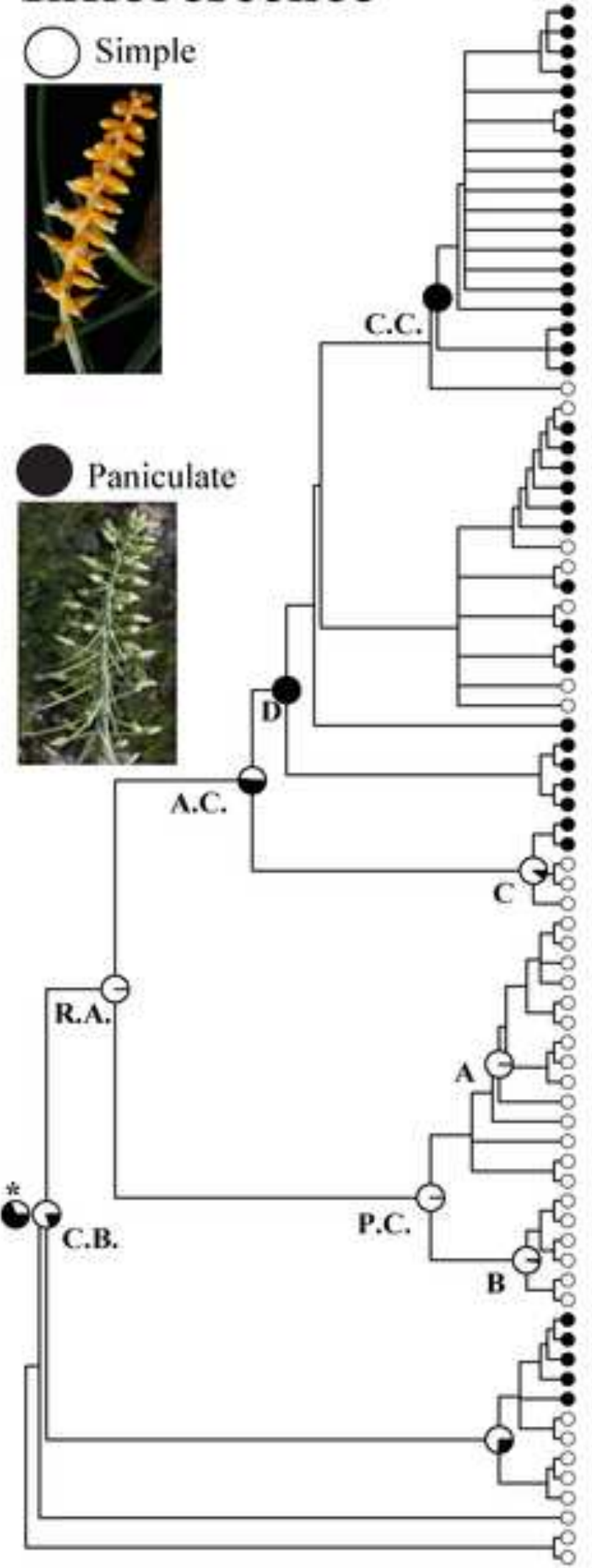

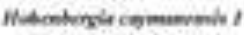

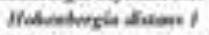
Thebelovgin tymedied $t$

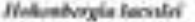

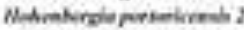
Matombrrxia enoilinds

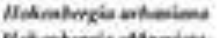
Whabedinger atervilat:

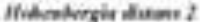
Natembrese fonvil

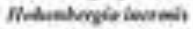

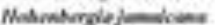
Mihaturgis monemin

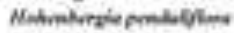
Mabielvereit on nor

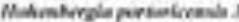

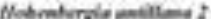

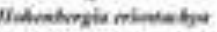

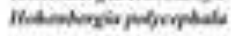
Animine Aitater?

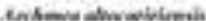

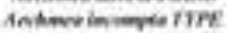

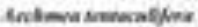

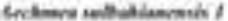
insome penmmina!

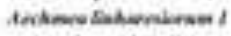

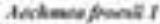

Antand incheneras

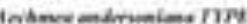

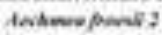

Achaver ameriest?

Andime herimmurai

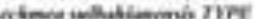

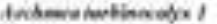

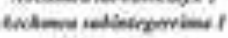

indame llas

Entima lingatar

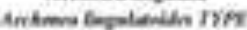

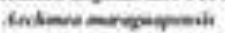

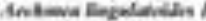

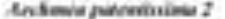

terkaresiridenter $n$.

Aredme Lendive.

Anderercentiolat

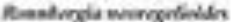

Ametergie wites

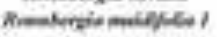

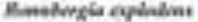

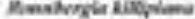

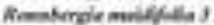

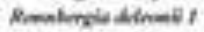

Remakrxia merimians:

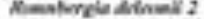

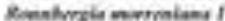

Riectumple rh nom.

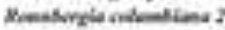

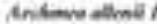

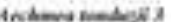

Aribion peralowe ?

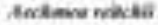

techimentalinge

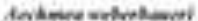

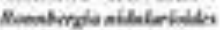

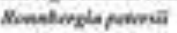

tentronepromi

intervidinderveta

Andenes destilies

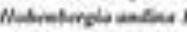

Lymonde vidoless

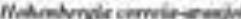

eniforanamaxs

insima melineglese

Creles initronis

An humer eadradi f

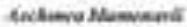

Andera trimensiles

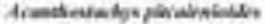

temperimasel

Alergentes monily

\section{Petal appendages}
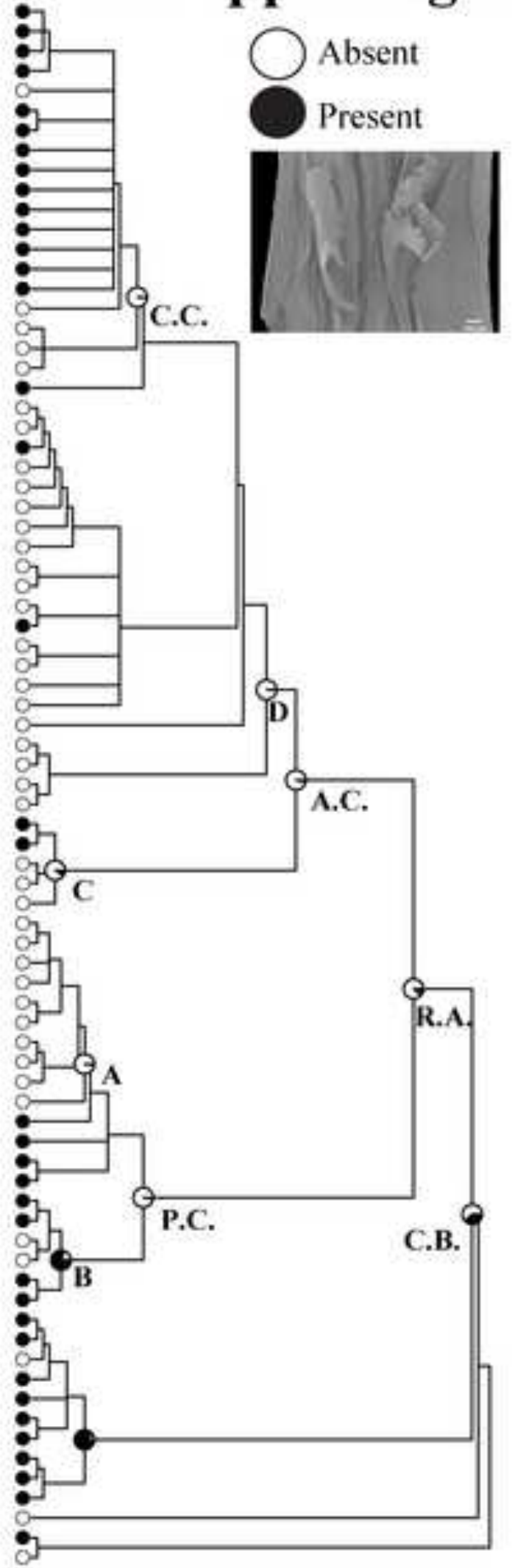


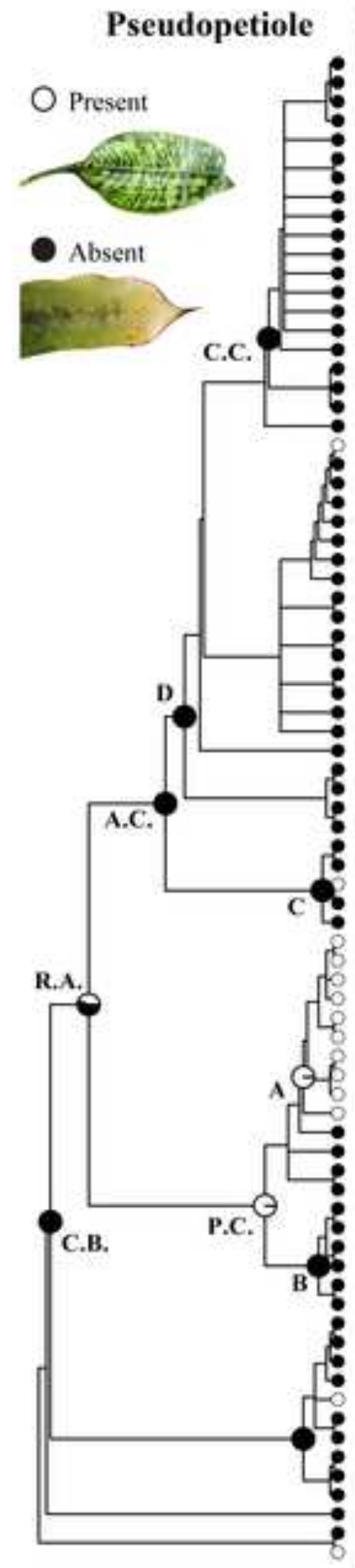

\section{Floral compression}

Compressed

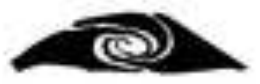

$-$

Terete

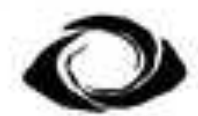

$=$

C.C.
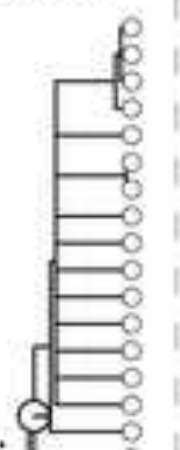

$\mathrm{O}$
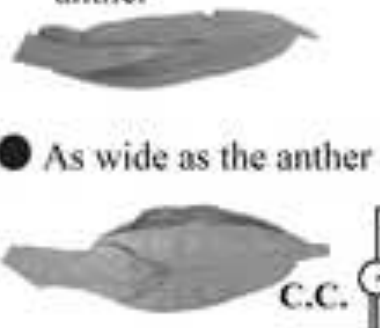

D

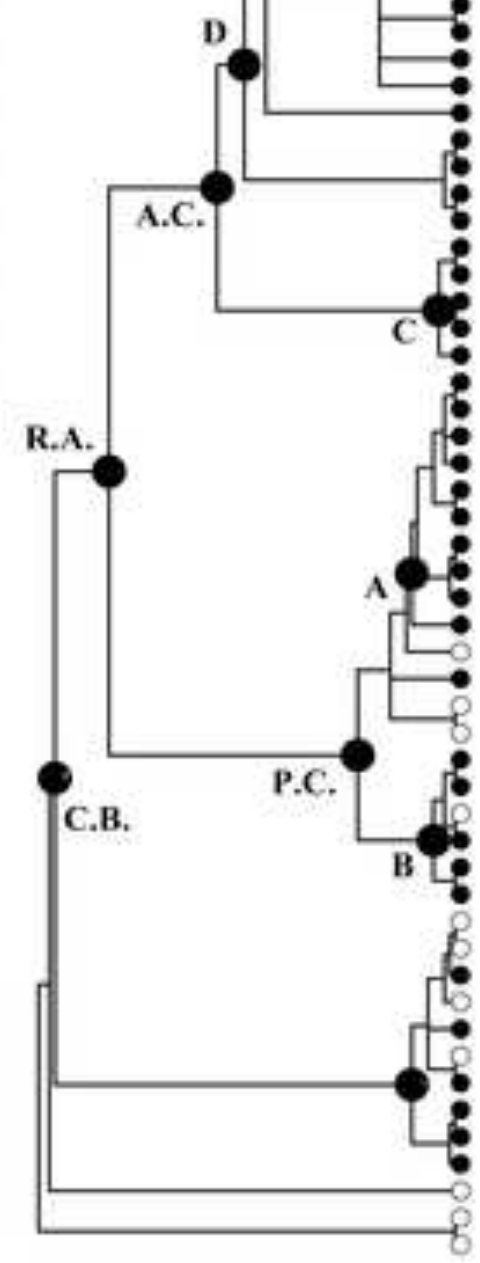

Narrower than anther

As wide as the anther

\section{Filament apex}

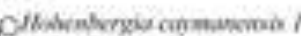

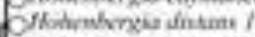

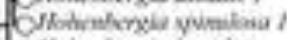

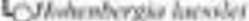

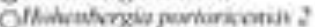

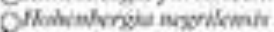

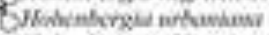

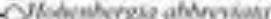

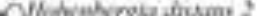

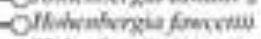

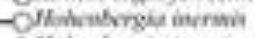

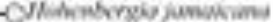

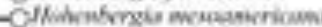

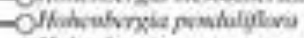

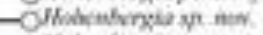

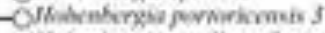

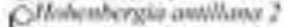

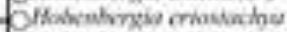

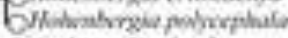

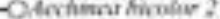

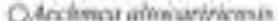

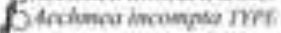

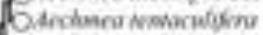

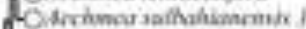

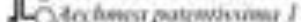

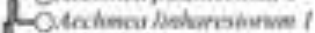

OAcchowo fromir I

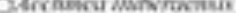

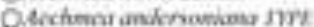

Siechenes hoair 2

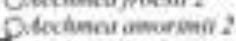

SMrehmes burkenarri!

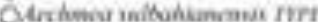

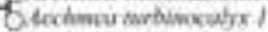

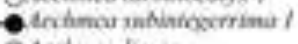

OAcchinaro hanow

OArchmov dogswis

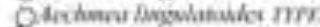

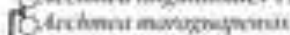

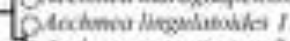

CAcchemor patraverangy 2

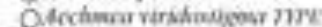

Sidrhami horotovest

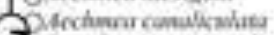

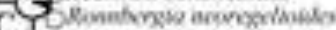

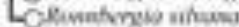

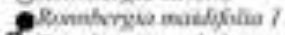

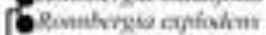

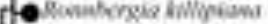

R.A.

R.A.

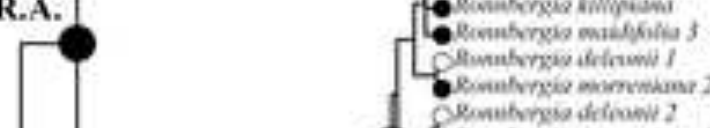

R.A.

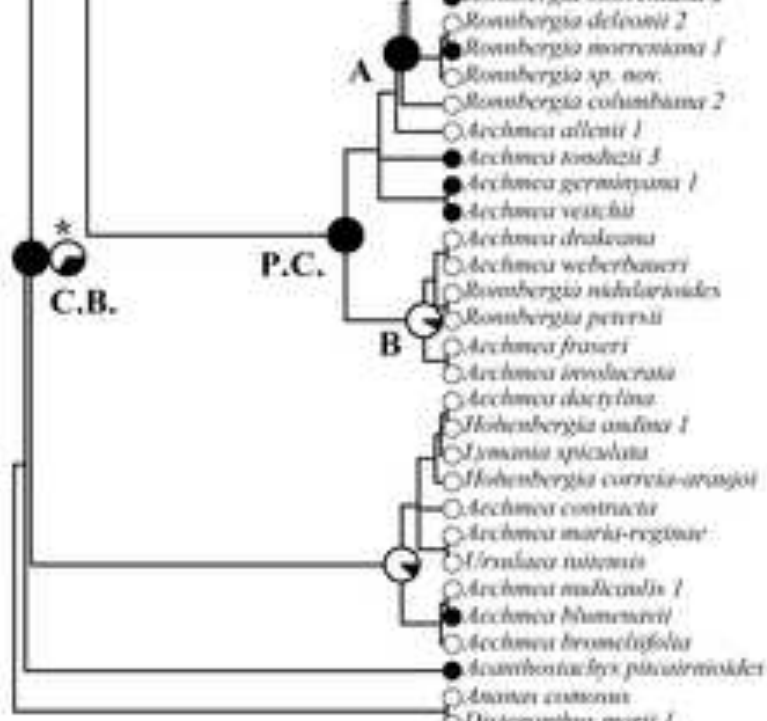


Flower length

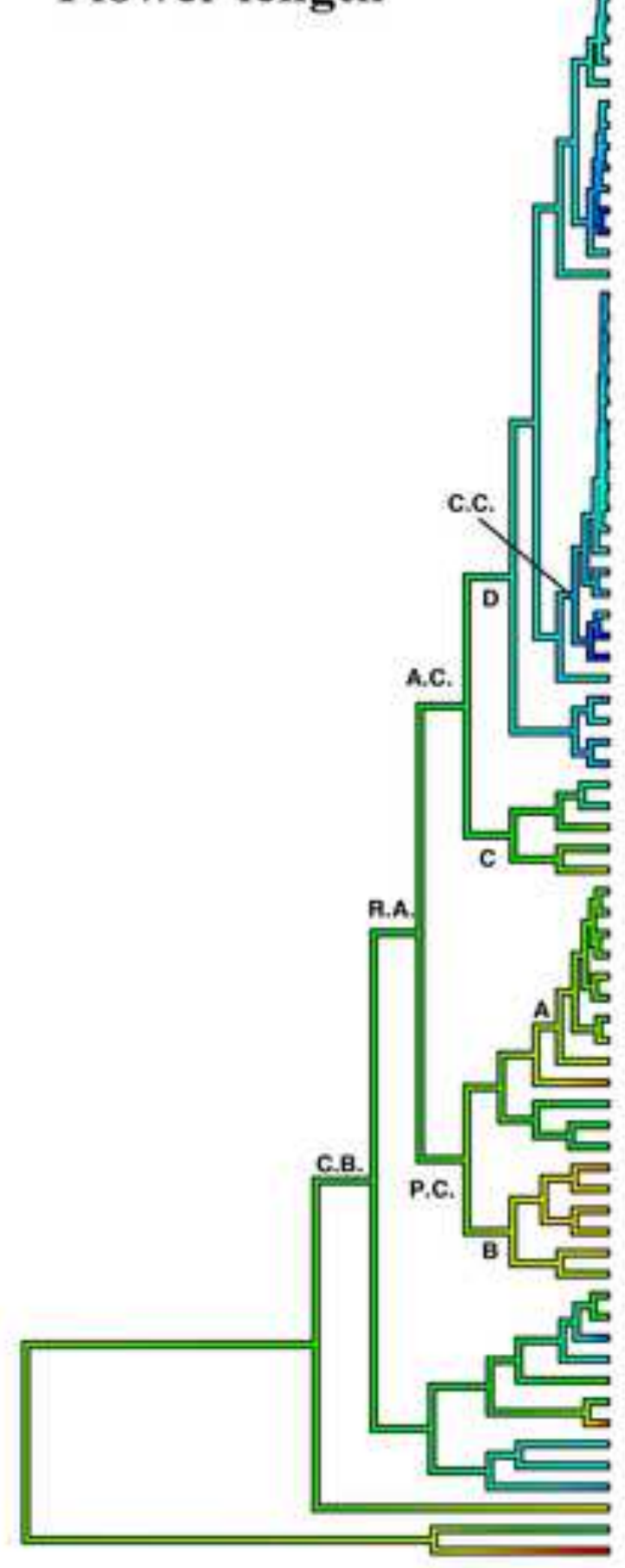

Log Flower leagth

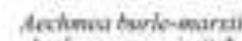
devhave unoviaw ? A coltinur isecoulion

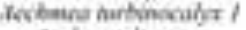

fechoris theser Acchmor frnati 2

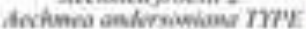
Aochencer ientrnareair

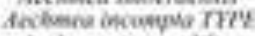

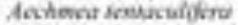
Aoslowst afencaririenta

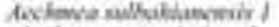

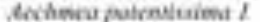

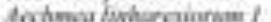

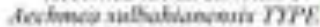

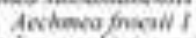

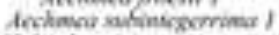

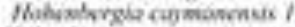

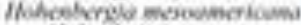
Mohrebnocrap and

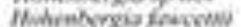

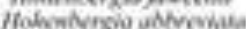

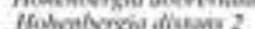
Mowntarons thavis thowrohorour Raviles Baterikntay diseass ?

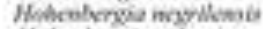

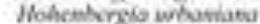
Wohrntarese incrmit

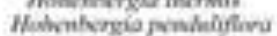

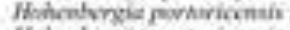

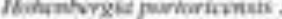
Hownengely dewWing ? tholombress polowentiols

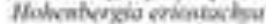
fectrove Nicalie? 2

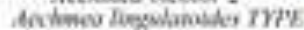

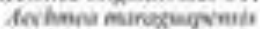

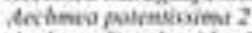
Aochenir Fenewlimider $I$

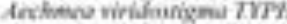
Arthnna dacosoms Nonnbryold shume

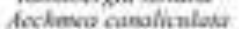

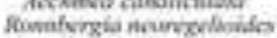
Jownfy gia nourgolanises

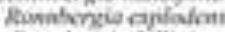
Rinestores fimyican

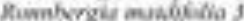

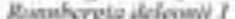
Roanhongla morrovized ?

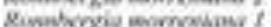

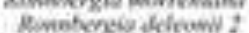

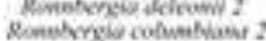

Nonebrgio cofmetwat

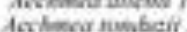

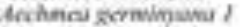
Anchmes wiviki

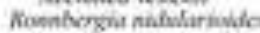
nuvolknxia percrais Anchavig drukiasp Ach heva wotyharer develos imeolwrion fecheno muser

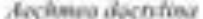
lMhimbrawr endiw ! tymanio spisculate

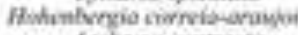
Arcitions inewhaste Aschenra acinia-roviede firulowe nuibruis enchorur Numovimai

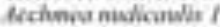

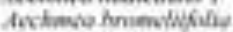

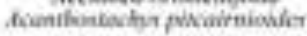
enavar coevasu Phascentibus mend i
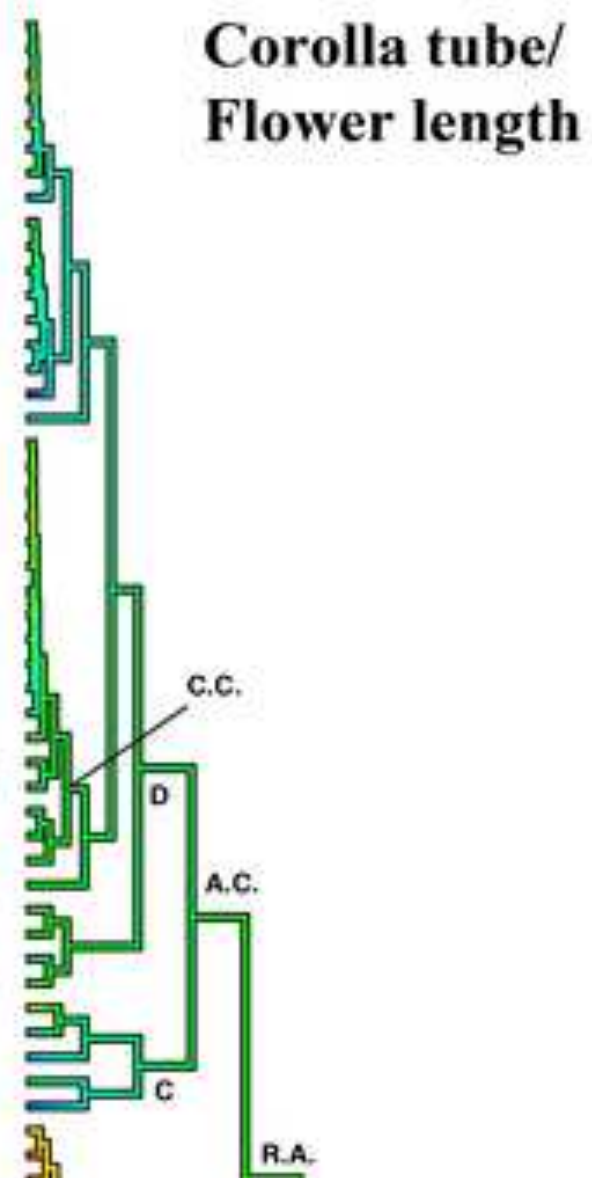

R.A.

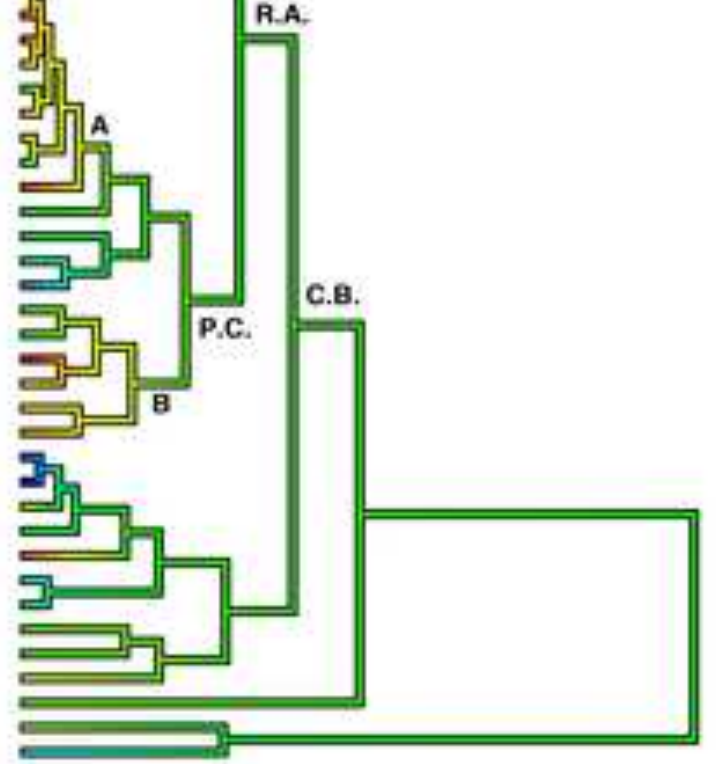

Log Coralla tobe/Flower length $-0.526$ 
Sepal connation/

\section{Flower length}

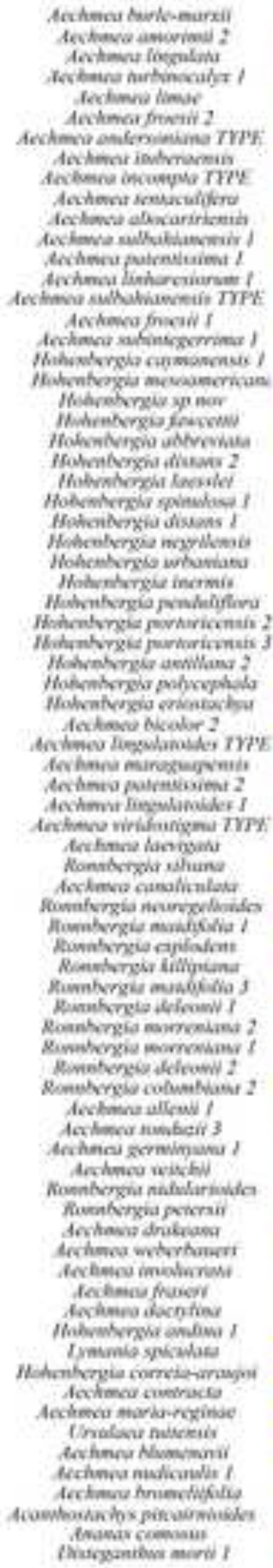

Aatene hark-enurxil Aeshave asicioned :

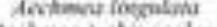

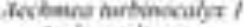
feclimed these Aecthor fractiv ?

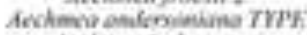

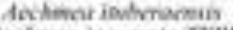

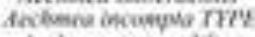

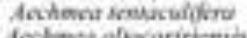
Aeslowe of wicarinienta

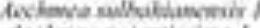
CWhent putrntsuimt ? Archmot linhorcuinesul Aechave suth atwiwieif TrF Aestawe fricaid I

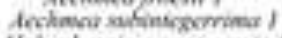

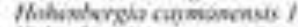

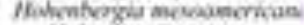
Mahrehoneiv spenor

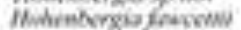

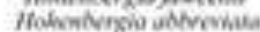
Pahaterenit dusvis 2

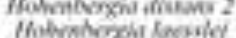

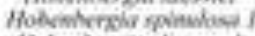

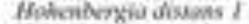

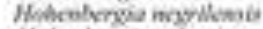

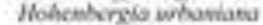
Mohrnhereve incrmit

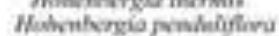

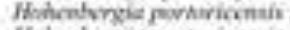

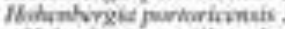

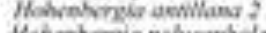
tholombress polowentiols

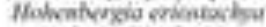
fectiong Aicalie?

Antwev liesolamidey rYH Aerkmen miroxegsmin Re⿳亠口冋es patrmessient 2 Achimur finswimolider I

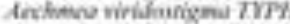
Arthrina dososint Nonnkerode shume

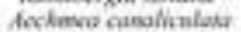
foconfergia nourexolinides

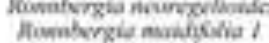

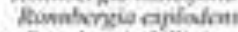

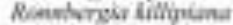
Rumbergu munotion s

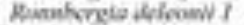
Roanhongla morrovias ?

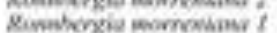
Ainsterneco diciew it

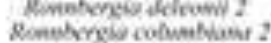
Aechasurallowit Acshancar nuberir 3

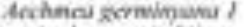
Anchmes wiviki

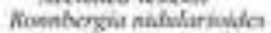
Nuvenkencia percrais Sechawas dnukraser Acheve wotyhar. Arables imiolwrim feclemo husere Axhmes dacntin. Mohvmbrawr endim I trasmiespicalas

Hehenteryia corretionoragen Acchimex coubracts

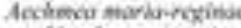
finalsur nuibreis enchener Numovenai Nerhnya nivilicaidis f

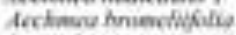

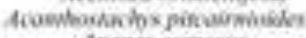
Cwawar comous

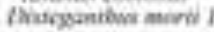

Sepal mucro/ Flower length

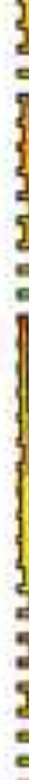

年
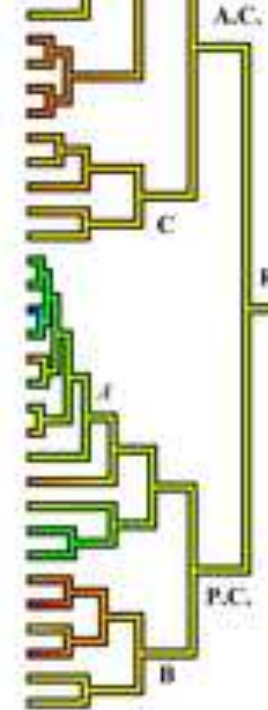

c.c.
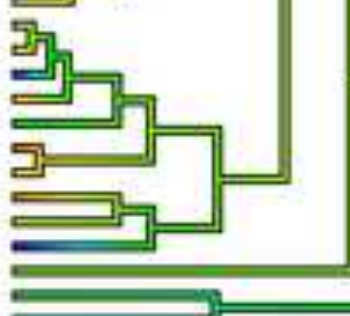

C.B.

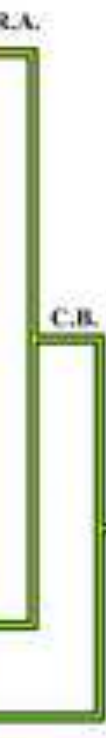

[

L.eg Sepal cenation/Floner length

0

0.231

lengthina.25

Log Sepal muero/Flower length $-1.265$ 

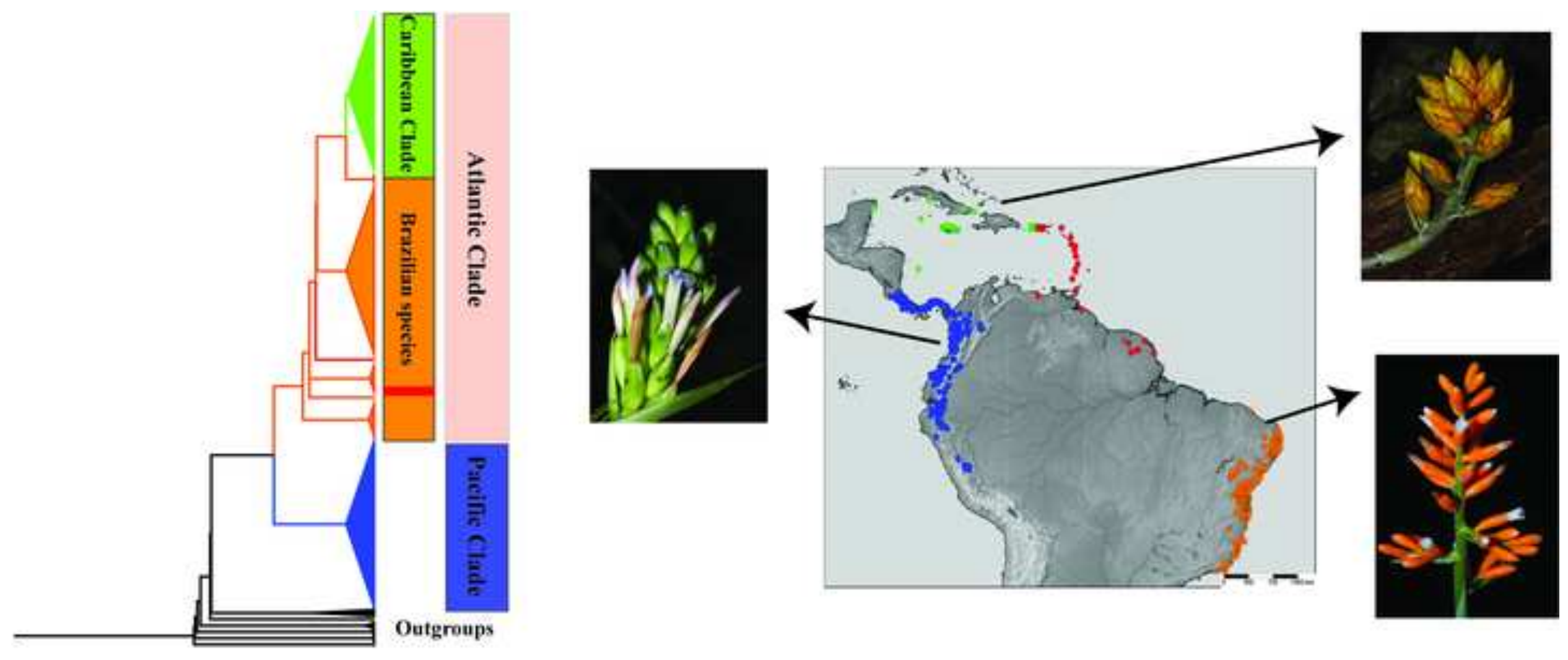